\title{
Transfer of Knowledge from Model Organisms to Evolutionarily Distant Non-Model Organisms: The Coral Pocillopora damicornis Membrane Signaling Receptome
}

Lokender Kumar $^{1}$, Nathanael Brenner ${ }^{1}$, Sam Sledzieski ${ }^{2}$, Monsurat Olaosebikan ${ }^{7}$, Matthew Lynn-Goin ${ }^{1}$, Hollie Putnam ${ }^{4}$, JK Yang ${ }^{5}$, Nastassja Lewinski ${ }^{6}$, Rohit Singh², Noah M. Daniels ${ }^{3}$, Lenore Cowen $^{7}$, Judith Klein-Seetharaman ${ }^{1 *}$

\author{
Affiliations: \\ ${ }^{1}$ Departments of Chemistry \& Physics, Colorado School of Mines, Golden, CO 80401 \\ ${ }^{2}$ MIT Computer Science \& Artificial Intelligence Lab, Massachusetts Institute of Technology, \\ Cambridge, MA 02139 \\ ${ }^{3}$ Department of Computer Science and Statistics, University of Rhode Island, RI 02881 \\ ${ }^{4}$ Department of Biological Sciences, University of Rhode Island, RI 02881 \\ ${ }^{5}$ Department of Department of Aeronautics \& Astronautics, University of Washington, Seattle, \\ WA 2400 \\ ${ }^{6}$ Department of Chemical and Life Science Engineering, Virginia Commonwealth University, VA \\ 23284 \\ ${ }^{7}$ Department of Computer Science, Tufts University, Medford, MA 02155
}




\begin{abstract}
:
With the ease of gene sequencing and the technology available to study and manipulate non-model organisms, the need to translate our understanding of model organisms to non-model organisms has become an urgent problem. For example, mining of large coral and their symbiont sequence data is a challenge, but also provides an opportunity for understanding functionality and evolution of these and other non-model organisms. Much more information than for any other eukaryotic species is available for humans, especially related to signal transduction and diseases. However, the coral cnidarian host and human have diverged over 700 million years ago and homologies between proteins are therefore often in the gray zone or undetectable with traditional BLAST searches. We introduce a two-stage approach to identifying putative coral homologues of human proteins. First, through remote homology detection using Hidden Markov Models, we identify candidate human homologues in the cnidarian genome. However, for many proteins, the human genome alone contains multiple family members with similar or even more divergence in sequence. In the second stage, therefore, we filter the remote homology results based on the functional and structural plausibility of each coral candidate, shortlisting the coral proteins likely to be true human homologues. We demonstrate our approach with a pipeline for mapping membrane receptors in humans to membrane receptors in corals, with specific focus on the stony coral, P. damicornis. More than 1000 human membrane receptors mapped to 335 coral receptors, including $151 \mathrm{G}$ protein coupled receptors (GPCRs). To validate specific sub-families, we chose opsin proteins, representative GPCRs that confer light sensitivity, and Toll-like receptors, representative non-GPCRs, which function in the immune response, and their ability to communicate with microorganisms. Through detailed structure-function analysis of their ligand-binding pockets and downstream signaling cascades, we selected those candidate remote homologues likely to carry out related functions in the corals. This pipeline may prove generally useful for other non-model organisms, such as to support the growing field of synthetic biology.
\end{abstract}

Keywords: remote homology, vision, immune system, opsin, Toll-like receptors, G protein coupled receptors

Running title: Coral Membrane Receptome 


\section{INTRODUCTION}

A bioinformatics functional genomics/proteomics pipeline for a newly sequenced non-model eukaryotic organism can (and should) seek to leverage the wealth of known information and annotation available for model species that are evolutionarily related. Due to the urgency of tackling species loss through environmental damage, many new non-model organisms are currently being sequenced, especially corals. Once the likely constituent genes have been identified (Ekblom \& Wolf, 2014)(Campbell et al., 2014), predicting if the relevant evolutionary functions of the non-model species genes are conserved or have diverged from their orthologous counterparts in the model species becomes directly relevant. Of course, there may be genes in the non-model organism that have no homologues, also referred to as the dark genome (Oprea, 2019). However, the goal of this paper is to maximally exploit existing knowledge from model organisms for the mining of non-model organisms for function. This is because this step is often quite difficult for organisms such as corals, where the host is 700 million years distant from the closest well-annotated model organism, even for many of the genes in closely related species to the model organism (Copper, 2001). It is particularly interesting that coral animals contain a surprising number of human homologs missing from fly and C. elegans (Kortschak et al., 2003).

Corals are complex organisms consisting of an animal host (cnidarian) and a microbiome with more than 20,000 species consisting of symbiotic algae, as well as bacteria, bacteriophages, fungi and viruses, collectively referred to as holobiont (Thompson et al., 2014). We consider here, as a case study, the membrane receptor proteins in corals. These are important families of proteins to study in corals because they have large potential to mediate the coral animal's interactions with its symbiont, microbiome and environment. Understanding these mechanisms in corals has become urgent. As a result of anthropogenic activities, both local and global, coral holobionts are declining rapidly. Mass coral bleaching, or the expulsion of the symbiotic algae due primarily to thermal stress driven by marine heatwaves, is resulting in substantial coral mortality (Hughes et al., 2018). A recent study assessed 100 worldwide locations and found that the annual risk of coral bleaching has increased from an expected $8 \%$ of locations in the early 1980s to $31 \%$ in 2016 (Hughes et al., 2018). Thus understanding the relevant parts of the coral animal genome that are relevant to interactions with their environment has become an urgent bioinformatics task, made possible by the recent availability of coral genomes for multiple species of both animal and symbiont. Fortunately, large classes of membrane receptor proteins have been preserved over time (de Mendoza et al., 2014), so there is a large body of prior knowledge that we can extrapolate from.

Given a protein of interest that has not been studied before, how much can be learnt from better studied proteins is a common question in biology. The answer lies in the sequence-structure-function paradigm, namely that a similar sequence usually maps to a similar structure and conserved function. This is the premise for the use of sequence alignments, for which many methods of analysis exist, the choice of which typically depends on how similar the sequences to be compared are. The problem with the sequence-structure-function paradigm is that relatively small changes in sequence can have dramatic effects on function, which is the 
basis for the evolution of protein families, where the overall fold is highly conserved, yet different members of the family can have different functions.

For many years, BLAST (Altschul et al., 1997) was the de facto standard homology search tool, as it provided comparable sensitivity to exact alignment methods such as Smith-Waterman (Smith \& Waterman, 1981) and early heuristics such as FASTA (Pearson, 1991) with much faster runtime performance. However, these methods, and even iterative methods such as PSI-BLAST, are unable to detect homologs in the "twilight zone" of homology, between 10 and 30\% sequence identity (Rost, 1999; Yona \& Levitt, 2002). The development of profile hidden Markov models (HMMs) such as HMMER (Eddy, 1998) and SAM (Karplus et al., 1998) improved remote homology detection performance, but as they still attempt to score a single query sequence against a profile-based HMM, they may miss homologs deep into the "twilight zone." A more recent advancement came in the form of HMM-HMM alignment (Söding et al., 2005) with HHpred in 2005, with further improvements resulting in HHblits (Remmert et al., 2011). These methods build a library of HMMs (or use an existing library) from families of nucleotide or protein sequences, and next build a query HMM from a multiple sequence alignment based on a BLAST-like search for similar sequences to the query, and use a variant of the Viterbi algorithm (Viterbi, 2009) to align the two HMMs according to maximum likelihood. $\mathrm{HHblits}$ was our choice for remote homology detection in this pipeline, as it combines state-of-the-art sensitivity to remote homologs with fast runtime performance, and is able to detect homologs in the range of $10-30 \%$ sequence identity. Given the roughly 700 million years of evolutionary divergence between cnidarians and humans, we could not assume that homologs would be of higher sequence identity. In order to avoid confusion with other organisms, we built a custom HHblits database for $P$. damicornis, and one of its symbiotic algae, Cladocopium goreaui (C1), formerly known as Symbiodinium (S.) goreaui (Clade C, type C1) (LaJeunesse et al., 2018) which we were able to query with human sequences of known function.

We know that corals adjust their behavior in response to external and internal cues, as illustrated by the following examples. Corals contract or extend their tentacles in response to light intensity (Levy et al., 2003). Coral larvae are known to prefer red over white surfaces for settling (Mason et al., 2011). Corals can fight, so they must be able to sense and attack the enemy or competitor (Yosef et al., 2020). Corals can distinguish organisms to tolerate (symbiosis) versus subjecting them to an immune attack to prevent disease (Mansfield \& Gilmore, 2019). Corals prefer to eat plastic over copepods which may relate to a sense of taste (Allen et al., 2017). Since corals manage $90 \%$ of their energy from symbiotic algae (Allen et al., 2017; Wooldridge, 2010), they must also be able to measure and regulate nutrient balance. The key question that arises from these observations is: what are the molecular mechanisms underlying these behaviors?

Generally, signal sensing and response reactions in biological systems depend on membrane receptor signaling systems. Receptor activation involves the detection of the signaling molecule (ligand) outside the cell when the ligand binds to the receptor protein present on the surface of the cell (Fig.1). The signal transduction stage involves the activation of the 
receptor (conformational change) leading to the chain reaction of the activation of intracellular proteins. These signal transduction cascades trigger specific cellular responses. Thus, membrane receptors most generally are proteins that are coupled to intracellular signal transduction cascades. There are two types of membrane receptors, sometimes referred to as type I and type II receptors (Fig.1). Type I membrane receptors usually contain one or two transmembrane (TM) helices, and often carry enzymatic activity in their cytoplasmic domains, such as tyrosine kinase receptors like the epidermal growth factor receptor. Type II membrane receptors are G-protein coupled receptors (GPCR) which exclusively contain a seven-TM helical bundle. There are also ion channels which change their permeability in response to external signals, but are usually not classified as receptors (Nemecz et al., 2016). Membrane receptors have three major structural domains: extracellular (EC), transmembrane (TM), and cytoplasmic (CP). We will discuss one example in depth for each of the two types of membrane receptor proteins. For the type II membrane receptor family, we have chosen the GPCR sub-family of opsins. As an example for type I membrane receptors, we will discuss Toll-like receptors (TLRs).

GPCRs respond to a large diversity of signals, from light in the opsin family to binding of hormones, neurotransmitters and even other proteins (Sakmar, 2010). Correspondingly, in humans, these receptors take a premier role as pharmaceutical targets and have thus been extensively studied (Sriram \& Insel, 2018). Signal transduction by GPCRs is via binding and activation of heterotrimeric $G$ proteins composed of alpha, beta and gamma subunits (Wettschureck \& Offermanns, 2005). GPCRs are responsible for the majority of cellular responses to external stimuli. Upon activation by a ligand, the receptor promotes the exchange of GTP for GDP in its partner heterotrimeric G protein complex, leading to the dissociation of the alpha and beta gamma complexes from the receptor and each other. The $G$ proteins then interact with other downstream effector proteins to mediate a cell response. In this study, we have used our remote homology detection pipeline to find human GPCR as well as G protein homologs in P. damicornis and Cladocopium goreaui (C1).

TLRs play a crucial role in innate immunity (Akira \& Takeda, 2004). These membrane glycoprotein receptors recognize and respond to a variety of microbial (viral, fungal, and bacterial) components such as lipopeptides (Kang et al., 2009), peptidoglycans and lipopolysaccharides (Park et al., 2009), flagellin (Park et al., 2009; W. S. Song et al., 2017), DNA (Ohto et al., 2018), and RNA (W. Song et al., 2015). TLRs consist of leucine-rich repeats (LRR), and the Toll/interleukin-1 receptor (TIR) domain (Narayanan \& Park, 2015). TLRs initiate signal transduction through interactions with TIR-domain containing adapters such as MyD88 (Dunne \& O'Neill, 2005), that in turn recruits interleukin-1 receptor-associated kinase (IRAK) via interactions through death domains (Chen \& Jiang, 2013). After phosphorylation, IRAK family proteins interact with the TRAF6 adapter. TRAF6 activates TAK1, a member of the mitogen-activated protein (MAP) kinase family (Dong et al., 2006), leading to the activation of NF-kB via kinase dependent signaling cascade involving IkB kinase complex (IKK- $\alpha$,- , and - $\gamma$ ) and MAP kinases (ERK, p38, JNK), resulting in the expression of target genes (Tang et al., 2021). Viruses and bacteria are abundant in seawater and live in close association with corals (van Oppen \& Blackall, 2019). The chemical crosstalk between corals and microbes plays an important role in coral growth and development. Corals need TLRs to communicate with microbes and it has been proposed that TLR signaling is conserved in corals (Williams et al., 
2018). In the present study, we used our remote homology detection pipeline to find human TLR protein homologs in $P$. damicornis and $C$. goreaui $(\mathrm{C} 1)$ to advance our understanding of coral innate immunity.

Using these two representative membrane receptor families, we will demonstrate that the stated problem of identifying remote homologues in non-model organisms is not just a remote sequence detection problem, but highlights the need for functional investigation of the putative proteins, which involves both systems and structural aspects of these proteins and their interaction partners. To this end, we focus on those positions in the alignments between model and non-model organism homologues that determine specificity of the respective protein's functions. We will discuss below first the common elements of the pipeline, how we determine the pool of all membrane receptors in $P$. damicornis, how we subdivide this broad group into type I and type II membrane receptors, and how we refined these two multi-subfamily groups into functional classes by analysis of two of them, TLRs and opsins, by way of identifying the specificity determination positions, followed by analysis of the downstream signaling proteins. 


\section{MATERIALS AND METHODS}

(a) Protein sequence retrieval. All non-P. damicornis and $C$. goreaui sequences were retrieved from the UniProt - Swiss-Prot Protein Knowledgebase, SIB Swiss Institute of Bioinformatics; Geneva, Switzerland (https://www.uniprot.org/). P. damicornis sequences (Cunning et al., 2018) were downloaded from http://pdam.reefgenomics.org/download/. C. goreaui sequences (Liu et al., 2018) were obtained from http://symbs.reefgenomics.org/download/.

Specific subgroups of sequences were identified and retrieved as follows and subjected to HHblits analysis as described in section (b).

(i) Human membrane receptor list. We have utilized two human membrane protein lists. The first one was published as the human membrane receptome in 2003 (Ben-Shlomo et al., 2003). We subjected the original list to an updated search in UniProt and retrieved 978 current UniProt entries, including GPCRs, provided in supplementary file-S1. The second was generated by using three alpha helix prediction tools followed by filtering of splice variants and clustering of the remaining genes (Almén et al., 2009). This list contains a total of 3,399 genes, including GPCRs, and is available from their supplement. The mapped $P$. damicornis entries (see below) are available in supplementary file-S2.

(ii) Human GPCR list. A comprehensive list of human GPCRs was extracted from an updated UniProt list of multi-species GPCRs (release: 2020_03 of 17-Jun-2020: 825 proteins (https://www.uniprot.org/docs/7tmrlist.txt). This list contained a total of 3093 GPCR sequences including 825 human GPCRs. See supplementary file-S3 for the extracted human GPCRs. The mapped $P$. damicornis entries (see below) are provided in supplementary file-S4.

(iii) $\mathbf{G}$ protein list. Sequences of human $\mathrm{G}$ proteins were obtained from UniProt using keyword search, resulting in 16 alpha chains, 5 beta chains, and 12 gamma chains (Wettschureck \& Offermanns, 2005). The complete list of these human proteins and their candidate $P$. damicornis homologues is provided in supplementary file-S5.

(iv) Toll-like receptor list. Protein sequences of TLRs of human (Akira \& Takeda, 2004) and other organisms, namely Drosophila (Imler \& Hoffmann, 2002), chicken (Nawab et al., 2019), frog (Ishii et al., 2007), and zebrafish (Kanwal et al., 2014), were retrieved from UniProt. TLR downstream signaling molecules (MyD88, TIRAM, TIRAP and TRIF) were also acquired from UniProt. The complete list with all the protein sequences used is provided as supplementary file-S6. The extracted $P$. damicornis TLR list is provided as supplementary file-S7 (note there is a separate sheet for each organism).

(b) Remote homology detection using HHblits: To enable organism specific searches, we created an online HHblits coral protein remote homology search tool (https://hhblits.cs.tufts.edu/), an installation of HHblits (Remmert et al., 2011) with genomic databases built for $P$. damicornis and $C$. Goreaui. Individual FASTA sequences were imported to this search tool and queries were run with an E-value cutoff of $10^{-3}$, single iteration, minimum probability of 20 (default), and with the minimum number of lines to show in the hit list expanded from 10 to 250. The jobID, email information, database information (e.g. P. damicornis) were submitted and the result output file was received by email or as batch predictions. Individual predictions contained the HHblits results of the submitted proteins in text format including 
protein sequence alignment, E-value, P-value, probability, column matched and score. In the case of GPCR, the result output was analyzed in a bidirectional fashion as follows. First, the top ranked $P$. damicornis hit was retrieved for each GPCR. Then a list of unique $P$. damicornis proteins were created from that, and the corresponding human GPCRs for which they appeared as top hits, provided as supplementary file-S4. For membrane receptors, the non-redundant lists of top ranked $P$. damicornis hits retrieved in the same way as for GPCRs are provided for both lists (supplementary file-S2). In the case of TLRs and G proteins, HHblits results were analyzed manually (see Results). For TLRs, top hits with $100 \%$ probability score were selected and analyzed separately for each model organism, i.e. human (Akira \& Takeda, 2004), Drosophila (Imler \& Hoffmann, 2002), chicken (Nawab et al., 2019), frog (Ishii et al., 2007), and zebrafish (Kanwal et al., 2014), before comparing them across organisms (Table 1). The list of $P$. damicornis hits for TLRs are provided as supplementary file-S7. A summary based on the frequency of occurrence of $P$. damicornis hits is provided in Table 1.

(c) PROSITE analysis: The most highly ranked $P$. damicornis sequences retrieved through $\mathrm{HHblits}$ were subjected to PROSITE analysis (de Castro et al., 2006) to identify the presence of conserved domains (https://prosite.expasy.org/). Protein sequences were submitted to the PROSITE user interface and the results were analyzed and grouped by combining the domain schematic provided by PROSITE.

(d) Transmembrane helix detection: In some cases, we verified the presence of a transmembrane region using TMHMM Server v. 2.0 (DTU bioinformatics, Department of Bio and Health Informatics) for the prediction of transmembrane helices (https://services.healthtech.dtu.dk/service.php?TMHMM-2.0).

(d) Homology-modeling: Homology models were generated using Swiss Model (https://swissmodel.expasy.org/), an integrated web-based service dedicated to homology modelling of proteins (Waterhouse et al., 2018). We used the target-template alignment function of Swiss Model and provided the reconstruction of the full TLR5 (3J0A) combining crystallographic and cryo-electron microscopy data created by (Zhou et al., 2012) as a template to model $P$. damicornis 9200. We have also modelled our potential matches for opsins (629, 2270, 12246, and 19775) using squid rhodopsin as a template (2ZIY) (Shimamura et al., 2008). The models were evaluated for their global quality estimate and local quality score as per Swiss Model guidelines. The models were downloaded and analyzed using PyMOL (version-2.3.4, Schrodinger, LLC). These proteins were further structurally analyzed for ligand binding pocket and Ballesteros-Weinstein numbering system. Ligand binding pocket residues in GPCRs were extracted from previous chemogenomic analysis (Surgand et al., 2006).

(e) Molecular docking studies of retinal with coral opsin homologs: Molecular docking was performed using retinal as the ligand with AutodockTools 1.5.6 (Harris et al., 2008). We standardized our docking experiments using squid rhodopsin with the following parameters: center_x=43.171, center_t=6.216, center_z=17.019, size_x=16, size_y=22, and size_x=26. Docking was performed by extraction after aligning the homology model with the squid rhodopsin space coordinates. The 'exhaustiveness' option was set as 32.0. The binding pocket 
was analysed using the Biovia discovery suite 2019 v19.1.0.18287 (Dassault Systemes Biovia Corp). Residues involved in the interactions for each model are listed in supplementary Table-S1.

(f) Multiple Sequence Alignment of $\boldsymbol{P}$. damicornis. Potential $P$. damicornis members of respective protein families were aligned to each other using MUSCLE (Edgar, 2004) (https://www.ebi.ac.uk/Tools/msa/muscle/) to examine if structurally relevant amino acids were conserved across family members. As an example, the alignment of opsin homologues in $P$. damicornis is shown in supplementary Figure-S2.

(g) D-SCRIPT Analysis. We initially identified candidate homologs in $P$. damicornis for the human alpha, beta, and gamma G proteins using HHBlits (Remmert et al., 2011) (hhblits.cs.tufts.edu). We took the union of top hits to identify 124 candidate alpha proteins, 207 candidate beta proteins, and 5 candidate gamma proteins. We used the human pre-trained D-SCRIPT (Sledzieski et al., 2021) model to predict interaction between all pairs of alpha-beta, beta-gamma, and alpha-gamma subunits. We performed the same analysis in Montipora capitata (Shumaker et al., 2019), where we identified 184 candidate alpha proteins, 253 candidate beta proteins, and 4 candidate gamma proteins. We created a mapping between $P$. damicornis and $M$. capitata proteins using BLAST (Altschul et al., 1997) and identified best-bidirectional-hits, i.e. a pair $(P, M)$ map to each other if $M$ is the best BLAST hit in $M$. capitata for $P$ and vice versa. We overlay the $P$. damicornis and $M$. capitata networks with each other using the mapping and identify as network-evidence candidate proteins where pairwise interaction is predicted between an alpha, beta, and gamma subunit forming a triangle in the network. 


\section{RESULTS}

(a) Development of a pipeline: addressing the challenges with existing methods: An overview of the pipeline we developed to address the goal of identifying the repertoire of membrane receptors in the non-model organism, the coral $P$. damicornis, using known information from the model organism, human, is shown in Figure 2. The first step is to create a list of human proteins representing the function of interest, here membrane receptors. A list of membrane receptors in human had been published previously (Ben-Shlomo et al., 2003), but when retrieving the sequences from the UniProt database, several entries were no longer valid. We manually retrieved the updated UniProt ID's by searching the database through protein names. The list of human membrane receptors obtained is available as supplementary file-S1. This list contains 978 human proteins. We also used another published list of membrane receptors (Almén et al., 2009), which contained 1352 human proteins reported using an outdated identifier format. Finally, a list of human GPCRs was extracted from a GPCR list in any organism from the UniProt database available at (https://www.uniprot.org/docs/7tmrlist.txt).

Initially, we used BLAST, as well as several multiple sequence alignment (MSA) based tools to retrieve $P$. damicornis homologues, but after inspection of the results we concluded that the alignments between human and $P$. damicornis sequences were poor as judged by the number of gaps and the fractions of sequences aligned (data not shown). We concluded that due to the low sequence similarity between human and $P$. damicornis, we required a remote homology detection tool. HHblits is the accepted gold standard for remote homology detection (Remmert et al., 2011). Thus, all three human membrane receptor lists were searched against $P$. damicornis using our implementation of HHblits, available at https://hhblits.cs.tufts.edu/, where our implementation of HHblits contains genome-wide template libraries of HMM models of all the genes in several coral animal and symbiont genomes (principally P. damicornis, M. capitata, plus the clade $\mathrm{C} 1$ symbioint).

When mapping these three sets of lists to the $P$. damicornis sequences using HHblits, it became clear that the same genes mapped to multiple human query sequences. This is because there are many members of membrane receptor superfamilies, e.g. receptor tyrosine kinases or GPCRs in each organism itself already. We therefore created non-redundant lists of the top ranked $P$. damicornis sequences. We obtained 374 unique $P$. damicornis sequences from the 978 human plasma membrane receptome (older list), 329 from the 1352 human membrane proteome (newer list) and 151 from the 825 human GPCRs. These lists and their respective overlap is provided in supplementary file-S2. Combining the three lists and eliminating duplicates appearing in more than one of the lists yielded a total of 446 unique $P$. damicornis sequences. While all 151 GPCRs were found in both membrane receptor lists, there were 111 and 50 non-GPCR receptors missed if we considered only the older human receptor list as compared to the newer one. Thus, we conclude that there are 295 non-GPCR and 151 GPCR candidates in the $P$. damicornis membrane receptome.

It is important to note that, in the majority of cases, none of the quantitative parameters of the sequence alignment was able to differentiate between the hits. In other words, it was not 
possible to automatically assign a best human homologue for any given $P$. damicornis sequence. This is because different members of protein families have diverged in humans, and are more similar to each other, than they are to any $P$. damicornis sequence, which is evolutionarily most distant to all of them.

Given the fact that many more human sequences map to a smaller set of sequences in $P$. damicornis raises the question which functional sub-categories of these superfamilies are present in P. damicornis. Clearly, sequence alone is not sufficient to answer this question, and therefore identifying which of the functionalities of a given sub-family of membrane receptors is present in corals requires an analysis of known functional properties. This requires domain expertise and can no longer be fully automated in contrast to all previous steps (Figure 2). This final step of the pipeline is demonstrated for two examples below and necessarily branches according to the functions of the proteins of interest. The opsin subfamily was chosen as a representative example for the type II membrane receptor, the GPCR pipeline (section (b) below). The TLRs were chosen to represent the type I membrane receptors (section (c), below).

\section{(b) GPCR (type II receptor) pipeline branch}

(i) Global analysis of GPCR families: The large GPCR family has been divided into subclasses based on a combination of pharmacological and sequence considerations, a classification which has been revised a number of times over the years (Surgand et al., 2006). Here, we use the clusters obtained with a chemogenomics approach based on the alignment of 30 critical GPCR positions supposed to face the ligand binding cavity (Surgand et al., 2006). Major classes besides olfactory receptors are Frizzled, Glutamate, Secretin and Adhesion families with the Class A rhodopsin family being split into 18 different clusters. When analyzing the human receptors for which $P$. damicornis sequences were found, these included chemokine, taste, glutamate, adrenergic, lipids, peptides, adenosine, amines, melanocortins, acids, chemoattractants, purines, frizzled, adhesion, prostanoids, and MAS-related receptors. Likely missing are melatonin receptors (with 2 low ranked options), vasopeptides, brain-gut peptides, SREB, secretin, opioid and glycoproteins. In all cases there are multiple human sequences that map to multiple (but less than humans) $P$. damicornis sequences. Detailed below is the evidence suggesting that $P$. damicornis can smell, taste and see light in sections (ii), (iii) and (iv), respectively.

(ii) Odorant receptors in $\boldsymbol{P}$. damicornis: We found 105 human olfactory receptors that map to pdam_00017423-RA, 27 that map to pdam_00020860-RA, 17 that map to pdam_00017300-RA, while pdam_0005244-RA, pdam_0005376-RA and pdam_00016463-RA had one hit each. This suggests that there are at least 6 olfactory receptors in $P$. damicornis.

(iii) Taste receptors in $\boldsymbol{P}$. damicornis: $\mathrm{HHblits}$ suggests that there are 15 remote homologs for the human taste receptors in the $P$. damicornis proteome: pdam_00004028-RA, pdam_00009436-RA, pdam_00000629-RA, pdam_00002659-RA, pdam_00013619-RA, pdam_00021435-RA, pdam_00022798-RA, pdam_00017219-RA, pdam_00001145-RA, pdam_00013621-RA, pdam_00010275-RA, pdam_00004281-RA, pdam_00002512-RA, 
pdam_00020500-RA, and pdam_00016973-RA. Transmembrane helix prediction using TMHMM confirmed the presence of 7 transmembrane helices in 13 out of 15 proteins. pdam_00002512-RA, and pdam_00009436-RA have more than 7 predicted transmembrane helices.

(iv) Vision receptors (opsins) in $\boldsymbol{P}$. damicornis: The HHblits result showed that the 11 members of the human opsin family mapped to $7 P$. damicornis sequences. However, there were other members of the Class A GPCR family that also mapped to the same $P$. damicornis sequences. To find out which of the HHblits remote homology predictions were likely true representations of visual functions, we analyzed the ligand binding pockets of these proteins. Light detection is the main function of rhodopsin. Therefore, the homologous proteins must have an ability to bind with a light sensitive retinal ligand and should possess a conserved ligand binding pocket. This pocket should show sequence similarity with human opsin protein. Considering this hypothesis, we analyzed the human opsin ligand binding pocket and compared our analysis with $P$. damicornis opsin homologues. We obtained the profiles of 30 cavity-facing amino acids used for clustering of the human GPCRs including opsin (Surgand et al., 2006). Thus, the approach outlined here for opsins can be extended to other GPCRs. The first step was to verify the presence or absence of these amino acids important for ligand binding in the $P$. damicornis sequences for the opsin family. The 30 residues are spread out throughout the sequence, and the Ballesteros-Weinstein numbering scheme used to identify aligned positions in GPCRs clearly showed that these residues are located across the 7 transmembrane helices. We compared these 30 residues against the top hit for OPSD and OPN5, and the result showed that only 11 out of 30 residues are the same between OPSD and their $P$. damicornis homologue.

Further, we had previously determined the minimal ligand binding pocket that is capable of exerting the function of a GPCR: transmission of the ligand binding signal to the downstream signaling proteins (Moitra et al., 2012). The approach used GREMLIN, Generative Regularized Models of Proteins, to identify long-range interactions from co-varying amino acid positions in multiple sequence alignments (Balakrishnan et al., 2011). GREMLIN learns an undirected probabilistic graphical model known as a Markov Random Field (MRF). Unlike HMMs, which are also graphical models, MRFs can model long-range couplings (non-sequential residues). We performed GREMLIN analysis on GPCRs, statistically evaluated different sizes of ligand binding pockets and found that a pocket as small as 4 residues still shows significant enrichment of edges over null. This means that four residues connect maximally to the rest of the protein orchestrating the global conformational change inherent to GPCR function and are required for signal transduction. Our analysis showed that 3 of these 4 residues are conserved across human opsin and the $P$. damicornis homologue. This is strong evidence that this protein is a functional GPCR.

Finally, GPCRs involved in vision require a lysine in a specific location of the ligand binding pocket to covalently attach via a Schiff base. The Schiff base is stabilized by another residue in the sequence, that is glutamic acid (E113), forming a counter ion to lysine K296, (highlighted by red arrows in Figure 5). We can see that the $P$. damicornis homologue contains the lysine required for retinal binding, but has a tyrosine instead of glutamic acid in the counter ion 
position. This substitution is expected to cause a shift in the absorbance maximum but not a loss of function. Thus, we can conclude that this $P$. damicornis sequence indeed represents a functional opsin protein, likely with an absorbance maximum different from that of rhodopsin and more like the OPN5 protein, which also has a tyrosine at this crucial position. Repeating this process for all of the $P$. damicornis homologues allowed us to eliminate proteins that did not fit the requirements of GPCR action or retinal binding function and narrow down the most closely related opsin protein. We predict that there are $4 P$. damicornis opsin proteins (in contrast to 11 human opsin proteins) and these are most similar to OPN5, OPSG, OPSX and OPSR. We conclude that $P$. damicornis can likely sense and respond to light and even distinguish colors. Previous research showed that the larvae preferentially settle on red as opposed to white surfaces (Foster \& Gilmour, 2016). Consistent with this behavioral finding, is the inclusion of the red opsin protein (OPSR) in our list.

(v) Homology modeling and molecular docking studies with opsin homologs: To confirm the structure and functional relationship of rhodopsin with putative coral rhodoposin homologs, we have performed structural modeling of the top coral rhodopsin hits using the squid rhodopsin structure as a template (Figure 6). We carried out molecular docking to these homology models that suggested that the retinal was indeed able to bind with the putative ligand binding pocket in the coral rhodopsin homologous structures. This suggests that these are strong candidates to be considered as coral rhodopsin homologs and may play an important role in light sensing mechanisms. We have summarized the details of the retinal interactions with squid rhodopsin and coral rhodopsin homologs in Supplementary Table 1.

\section{(c) GPCR binding partner: G Proteins}

To gather further evidence that the proteins identified were functional opsins, we investigated their function, namely binding and activation of the $G$ proteins upon ligand binding (or light activation of the retinal ligand in the case of opsins). $G$ proteins are heterotrimeric proteins consisting of alpha-, beta- and gamma-domains. There are 16 different alpha chains, 5 beta chains, and 12 gamma chains in humans (Wettschureck \& Offermanns, 2005), and their UniProt ID's are provided in Supplementary File S5, tab 1. HHblits search of the alpha and gamma chains yielded six potential $P$. damicornis alpha chains and five potential gamma chains, see Supplementary File S5, tab 2. We were unable to retrieve potential beta chains reliably, due to the beta propeller structure of the beta chains being a very common structural motif found across multiple protein families.

(i) Multiple Sequence Alignment of $\boldsymbol{P}$. damicornis alpha chains: The potential $P$. damicornis alpha chains were aligned with the human G-alpha subunit that binds to rhodopsin, called transducin, with gene symbol GNAT1 using MUSCLE (see Methods) to examine if structurally relevant amino acids were conserved. Amino acids of GNAT1 which interact with rhodopsin, GNB1, and GTP were identified from co-crystal structures (PDB ID: 6OY9, 1TAD) by selecting residues within $5 \AA$ of the relevant structure in PyMOL. These residues are highlighted in Figure 6A using boxes colored orange, blue, and green, respectively. The alignment shows that the GTP binding pocket residues are the most conserved, the receptor binding residues are the 
least conserved, and the beta chain binding residues are more conserved than the receptor binding residues but less conserved than the GTP binding residues. This is to be expected, as the GTP pocket will need to bind to the same structure in corals as it does in humans, whereas the receptor and beta chain binding residues will need to bind to coral receptor and beta chain homologues, which will be structurally different. Because the conservation patterns are similar across all $5 P$. damicornis G-alpha candidates, we are not able to select a top candidate from this pool that is most likely representative of the rhodopsin-binding G-alpha subunit, transducin (GNAT1).

(ii) Network analysis of putative $\boldsymbol{P}$. damicornis $\mathbf{G}$ protein subunits: To overcome the challenge that sequence alignment alone was not sufficient to narrow down the choices of $P$. damicornis sequences related to $G$ proteins, we leveraged computational prediction of protein-protein interactions (PPI) to characterize the relative likelihood of the top $P$. damicornis hits being truly involved in GPCR binding activity. Applying D-SCRIPT (Sledzieski et al., 2021), a recently introduced sequence-based deep learning model for PPI prediction, we performed two complementary PPI analyses. In the first, we performed an all-vs-all computational screen of interaction between all the candidate G-alpha, beta and gamma proteins in $P$. damicornis, reasoning that the true positive hits will display the expected interaction patterns of alpha-beta and beta-gamma binding. Our predicted PPIs broadly conformed to this expectation, with pdam_00017900-RA, pdam_00011071-RA, pdam_00023984-RA, pdam_00007710-RA, pdam_00014456-RA, pdam_00011840-RA being the strongest candidates for alpha subunits, pdam_00000168-RA the strongest candidate for a beta subunit, and pdam_00000526-RA the strongest candidate for a gamma protein. To gain further confidence in our estimates, we also performed a similar screen of $G$ protein subunits in $M$. capitata (Figure 6C) and assessed if homologous pairs across the two coral species (estimated by a bidirectional best hit analysis) had similar PPI patterns (see Methods). These results further supported our estimate, as the same connectivity patterns observed in $P$. damicornis are also observed between homologues in M. capitata.

(iii) Conservation of structural interfaces in $\mathbf{G}$ protein complexes: To further confirm the predicted $G$ protein complex compositions, D-SCRIPT was then used to assess the structural plausibility of individual G-alpha candidates in $P$. damicornis. We performed an in silico mutagenesis study of each G-alpha candidate, evaluating these mutations by how they changed the D-SCRIPT score for interaction with candidate G-beta proteins pdam_00000168-RA and pdam_00014586-RA (Figure 7). Reasoning that a conservative test would be to require the same binding mechanism as seen in human G-alpha-beta interaction, we first aligned candidate G-alpha protein sequences in P. damicornis against human G-alpha proteins GNAT1, and used the multiple sequence alignment to identify the residues in coral G-alpha where the corresponding location in GNAT1 is known to play a role in binding to G-beta proteins. We tested if random in silico mutations at these locations had a particularly deleterious effect on the likelihood of PPIs with coral G-beta candidates (average of 50 trials). We compared these likelihoods to the original predicted probability of interaction, and the predicted probability of interaction after in silico mutations at random sites (average of 50 trials). Two candidates, pdam_00014456-RA and pdam_00011071-RA, showed sharply decreased likelihood of a PPI 
occurring specifically when the sequences were mutated at putative binding locations -suggesting a binding mechanism similar to human G-alpha-beta interaction is conserved in determining the interaction likelihood of coral G-alpha-betas.

\section{(d) Toll-like receptor (TLR, type I receptor) pipeline branch}

(i) TLRs in P. damicornis: After having demonstrated that there are functional GPCR (aka type II receptor) proteins and pathways in $P$. damicornis, we next investigated a representative of the type I receptors, namely TLRs. Because there are large differences in the numbers of TLRs in different organisms, we retrieved TLR sequences not only from humans (Akira \& Takeda, 2004), but also zebrafish (Akira \& Takeda, 2004; Kanwal et al., 2014), frog (Ishii et al., 2007), chicken (Nawab et al., 2019) and Drosophila (Toll proteins) (Valanne et al., 2011). After subjecting these sequences to $\mathrm{HHblits}$ prediction, we extracted all coral proteins that showed a minimum of $100 \%$ probability, and grouped them by their homology to a given organism. The results are summarized in Table 1. P. damicornis proteins 22934, 22930, 11599, 9200, 14109, 17966, and 13021 were observed as homologues to at least one TLR from each of the five model organisms studied. Because many type I receptors are often composed of multiple domains, we then subjected these proteins to PROSITE analysis in addition to homology modeling.

(ii) PROSITE analysis showed similar domain signatures in $\boldsymbol{P}$. damicornis proteins: PROSITE analysis was used to identify domain structures within putative TLRs. Figure 3A illustrates that in human TLRs, there are multiple copies of leucine rich repeat (LRR) domains present on the extracellular side of the receptor and a Toll/interleukin-1 (IL-1) receptor (TIR) domain in the intracellular side in human TLRs. In contrast, $P$. damicornis 22934, 22930, 15883, 15877, 11734, and 11599 were devoid of LRRs and only displayed the TIR domain. This suggests that these proteins may not belong to the typical TLR family. On the other hand, PROSITE analysis of $P$. damicornis 14109 and 17966 homologues showed a large number of LRRs, plus a cadherin domain, EGF_CA (Calcium-binding EGF domain), Thrombospondin, type 3 repeat (TSP3), Thrombospondin C-terminal domain profile (TSP_CTER) domains on the extracellular side and the TIR domain on the intracellular side. Because of these additional domains, it is possible that these are TLRs but with different or additional functions as compared to their endosomal human counterparts. A third domain composition was revealed by PROSITE analysis of $P$. damicornis 737 which only had LRRs and no TIR domain. Therefore, this homologue was rejected as a TLR candidate. The only domain composition similar to that of human TLRs was observed for $P$. damicornis homologue 9200, which included multiple LRRs in the extracellular domain and a TIR domain in the cytoplasmic domain. For further analysis, we selected 9200 for homology modeling due to its matching profile with human TLRs.

(iii) Structural similarities between human TLR5 and $\boldsymbol{P}$. damicornis TLR: Swiss Model matching for query $P$. damicornis protein 9200 retrieved human TLR5 (3j0a) as the top hit. We refined the model by removing several missing regions from the coral TLR model (Figure 4). Using TMHMM with 9200, we identified a transmembrane helix region (649-671) between the extracellular and the intracellular region, supporting the organization as a typical type I receptor. 
bioRxiv preprint doi: https://doi.org/10.1101/2021.10.18.464760; this version posted October 28,2021 . The copyright holder for this preprint

(which was not certified by peer review) is the author/funder, who has granted bioRxiv a license to display the preprint in perpetuity. It is made available under aCC-BY 4.0 International license.

(iv) MyD88 homologue as the possible downstream partner: TLRs utilize multiple adapter proteins to transmit the signal to the inside of the cell, namely MyD88, TIRAM, TIRAP and TRIF adaptor proteins. Our HHblits results of these proteins showed presence of a coral homologue only for MyD88. 


\section{Discussion}

We present a general pipeline applicable to any non-model organism to explore functions based on detectable homology to critical proteins in humans or other model organisms. The strategy involves the following steps (Figure 2). The first step is to create a list of related proteins representing a function of interest such as membrane receptors, or ion channels, or proteins involved in wound healing etc. Often, we can use computational expansion of proteins we know represent this function, but depending on the complexity and relatedness of the group of proteins, it may require manual selection. Once a suitable group of proteins has been established, we subject this list of sequences to remote homology detection, using HHblits. This usually yields a large collection of putative distant homologs. Traditionally, you would choose the top ranked hit and assume that this hit represents the best match to the query's function. In the case of evolutionarily distant species, this approach fails because a protein family may have already diversified within each individual organism. There can be a smaller or a larger number of family members in one organism as compared to the other organism, and this may represent presence/absence of a particular function or sub-function. This creates the challenge that we need to distinguish which remote homologues in fact will have conserved the function of interest of the original query. The next step is therefore to identify the best bidirectional match from the candidate protein pairs to create a shortlist. So far, these steps can all be fully automated. Next, however, we need to assess the structural plausibility of each possible match, and this requires manual investigation that depends on the availability of structures and expert knowledge on the function of interest. We can think of this as casting a very wide initial net based on recovering a weak signal of sequence similarity, and then using 3D structural models to focus attention on a particular small number of functionally important residues that can provide a signature for function conservation. This sequence signature is based on a protein-protein interaction or a protein-ligand interface. We have presented several tailor-made approaches to this challenge. In the case of GPCRs, we looked at specificity determining positions (Capra \& Singh, 2007; Kalinina et al., 2004), which can then be confirmed by doing 3D structural modeling, to check that the active sites and binding pockets that are expected, should the functional role of the protein be conserved, are indeed present. In the case of $G$ proteins, we derived function based on protein-protein interactions, where we have used our recent deep learning method (Sledzieski et al., 2021) to perform in silico mutagenesis studies to further help us distinguish sequences which are likely to allow us to correctly transfer functional annotation from their human homologs from those that may have other functions. In the case of TLRs, we have used PROSITE to identify presence or absence of entire domains within the sequences, and used expert knowledge to evaluate if the location of these domains matches the functional expectation (e.g. if the domain faces the inside or outside of the cell). To this end, we compared PROSITE domain family predictions for the human query proteins and the putative coral homologues. All human TLR showed the presence of LRRs in the extracellular domain, and TIR domain in the cytoplasmic region. In contrast, in the 13 putative coral homologues, only one coral sequence of these candidates shows the expected (see Figure 1, type I receptor organization) extracellular LRR and intracellular TIR domain, separated by a transmembrane helix. This finding allows us to narrow down the candidate list to a single sequence. 
The availability of three-dimensional structures for one or more members of the protein family of interest opens the possibility for in-depth structure modeling using homology. Although the quality of homology models depends on the degree of sequence conservation, structurally aligning remote sequences goes a long way in interpretation of their structure conservation as long as we can have confidence in the alignment. For example, despite near negligible sequence conservation between rhodopsin and metabotropic glutamate receptors, the most distant members of the GPCR family, we were able to predict the pharmacological outcome of ligand binding based on structural alignment (Yanamala et al., 2008). With the continuous improvements in de novo structure prediction (Jumper et al., 2021), this task will become more and more feasible even for proteins that do not have any homologous structures available, i.e. for which no structural template can be found.

One challenge not currently addressed by our pipeline is the identification of de novo proteins with de novo functions. While homology modeling allows us to detect proteins that are present (with mutations) in both species, we acknowledge that just as some proteins novelly evolved in vertebrates and are not present in cnidarians, there is the possibility of complexes that novelly evolved in corals, which this approach cannot detect.

The results of our study have several biological implications. Cnidarians as evolutionarily early animals offer great opportunities to study the evolution of important biological functions, such as sensing and signaling, and understanding host-microbe communication. TLRs are used for molecular communication with microbes. These receptors interact with specific microbial antigens and play a major role in innate immunity. We obtained strong evidence for TLR presence in $P$. damicornis, in line with several previous reports suggesting the presence of TLR mediated signaling in corals. Analysis of a cnidarian genome indicated the presence of immune related genes and the presence of Toll/TLR pathways, membrane attack proteins, and complement pathway associated signaling molecules (Miller et al., 2007; Nyholm \& Graf, 2012). RNA-Seq data also supports the ability for immune responses in corals (Anderson et al., 2016; Cunning et al., 2018). One study showed that the muramyl dipeptide (MDP), a bacterial cell wall component, was found to trigger the up-regulation of GTPases of immunity-associated proteins in Acropora millepora (Weiss et al., 2013). Finally, the transcriptomic expression during thermal stress and pathogen challenge with Vibrio coralliilyticus in $P$. damicornis also supports the regulation of Toll/TLR and prophenoloxidase and complement pathways (Vidal-Dupiol et al., 2011). We now add detailed protein structural analysis to these reports, and also provide evidence that $P$. damicornis carries the gene for the TLR adapter protein, MyD88 ( $P$. damicornis id 15711).

Of particular note is that our results suggest a much smaller number of proteins involved in TLR signaling than in the model organisms human, chicken, zebrafish, frog, and Drosophila. We predict that there may only be a single, unique TLR homolog in the coral $P$. damicornis that exhibits all the features expected for TLRs, and is most similar to TLR5 in human (Figures 7,8). For comparison, Table 1 shows the frequency of each $P$. damicornis protein for a specific TLR protein in various model organisms. Furthermore, we have found only one (MyD88) of the four 
known adapter proteins MyD88, TIRAM, TIRAP and TRIF. This suggests the presence of a less diversified and simpler TLR signaling pathway in coral as compared to higher eukaryotes.

A similar conclusion was reached in the analysis of the large and diverse GPCR family. The human genome alone encodes 825 GPCRs, while we only found 151 GPCRs in $P$. damicornis. This is also reflected in the analysis of the opsin subfamily which has 11 members in human and we predict 4 in $P$. damicornis. Looking at reports of GPCR family size in evolutionarily early organisms suggest that there is a dramatic expansion in the numbers of GPCR when transitioning from unicellular to multicellular organisms. For example, choanoflaggelata have only 10 GPCR (Hake, 2019), while the Placozoan Trichoplax adhaerens has 420 (Srivastava et al., 2008), while sponges have 330 (Krishnan et al., 2014), Nematostella vectensis corals have 890 (Schiöth et al., 2010) and hydra has 1200 (!) (Chapman et al., 2010). Evolutionary analysis of the sub-families suggests that the doubling that takes place between Trchoplax adhaerens and Nematostella vectensis is roughly maintained and most sub-families remain relatively constant in their size distributions, with the Class A rhodopsin-like family being the largest in all species (Jékely, 2013; Nordström et al., 2011).

Taken together, both TLR and GPCR analysis suggest that $P$. damicornis represents a transition species that carries the minimal number of essential components for signaling and innate immunity, while additional functionality and fine tuning is achieved through diversification of this small pool of proteins in higher evolved organisms. Thus, being able to differentiate between early basic versions of a given function and finding the reasons for the need to diverge emphasizes the utility of this method assuming the best hit is the most functionally relevant hit. This may help to identify possible functions for currently not conclusively annotated proteins in $P$. damicornis and other non-model organisms. 
bioRxiv preprint doi: https://doi.org/10.1101/2021.10.18.464760; this version posted October 28, 2021. The copyright holder for this preprint (which was not certified by peer review) is the author/funder, who has granted bioRxiv a license to display the preprint in perpetuity. It is made available under aCC-BY 4.0 International license.

\section{Acknowledgments}

This work was sponsored by NSF grants HDR: DIRSE-IL 1940169 and RAPID 2031614. 
Figures and Tables

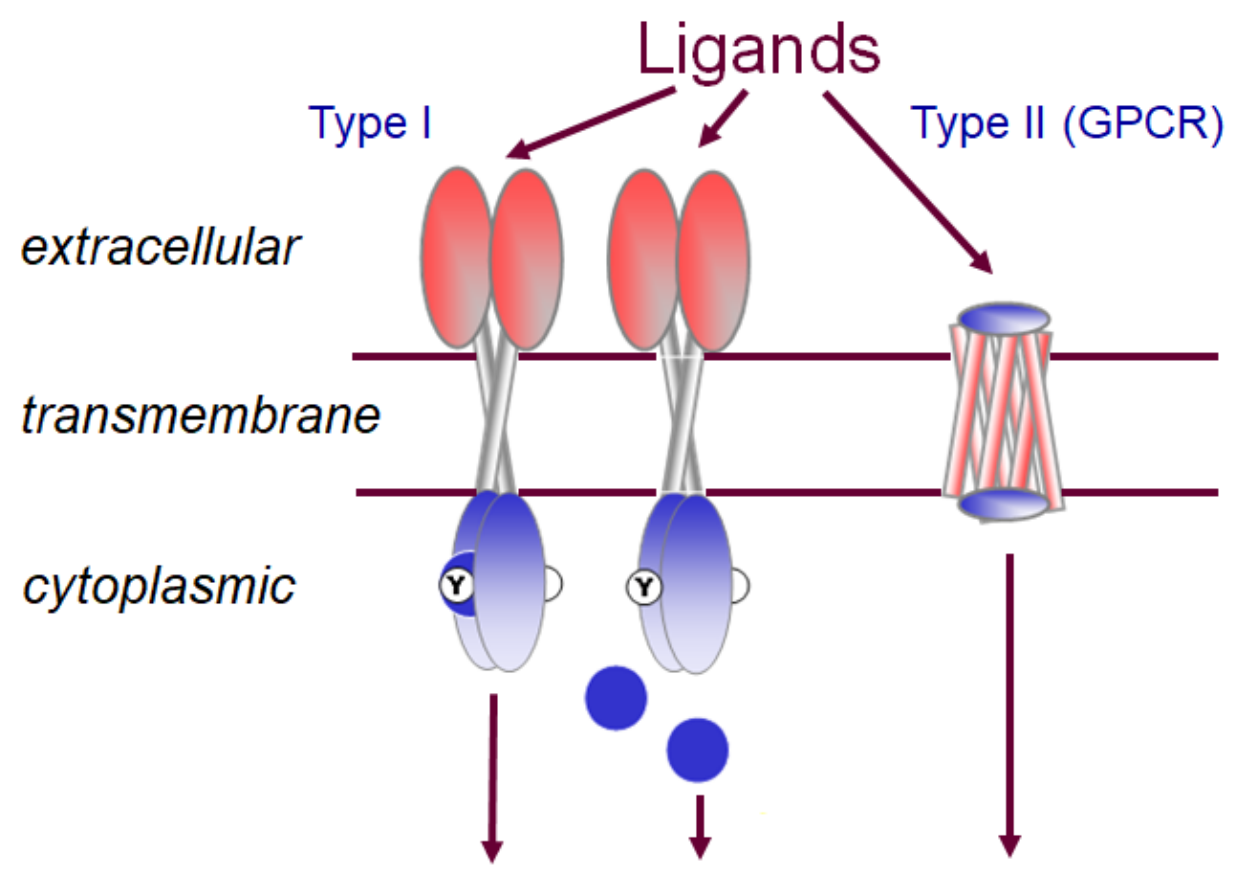

\section{Signal Transduction Cascades}

Figure 1. Schematic representation of type I and type II membrane receptors in signal transduction. 


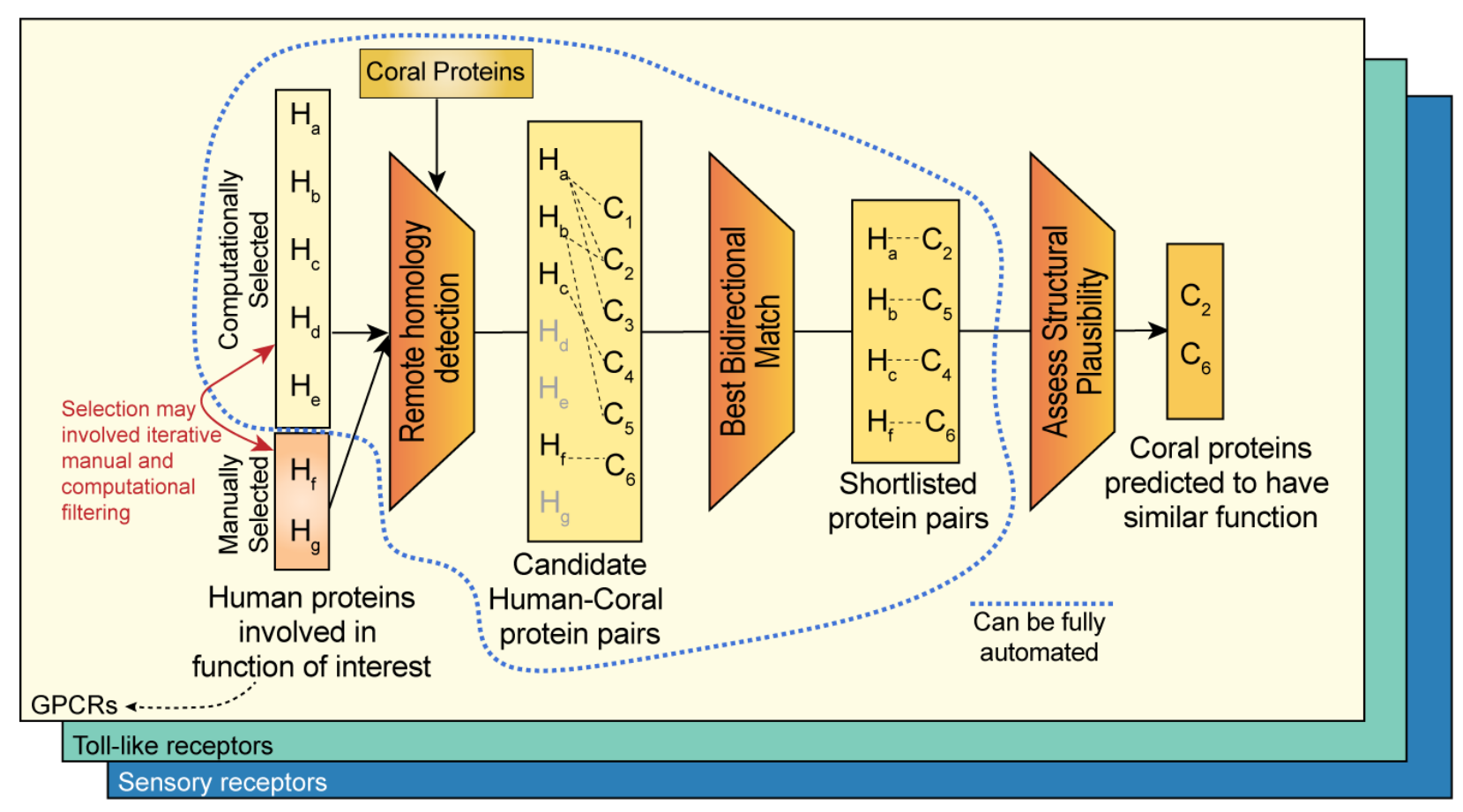

Figure 2. In silico protein prediction methodology. 

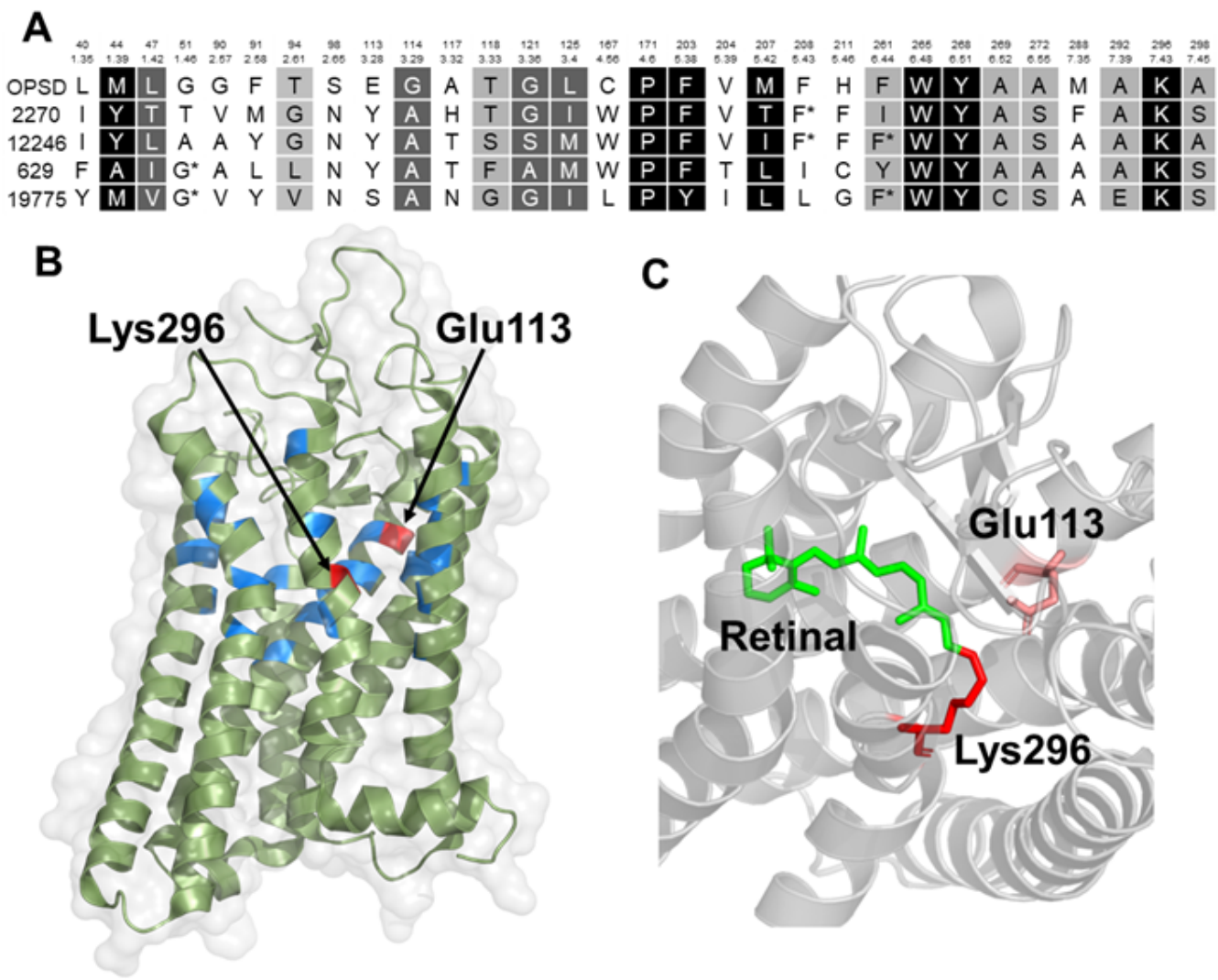

Figure 3. Sequence alignment and active site analysis of rhodopsin. (A) Alignment of rhodopsin and coral proteins and scoring based on Ballesteros-Weinstein (colored according to the degree of similarity: white foreground/black background, $100 \%$; white foreground/grey background, > $80 \%$, black foreground/grey background, $>60 \%$ ). (B) Active site of bovine rhodopsin showing the residues involved in active site. (C) Active site showing the interaction of retinal with Lys296 and Glu113. 

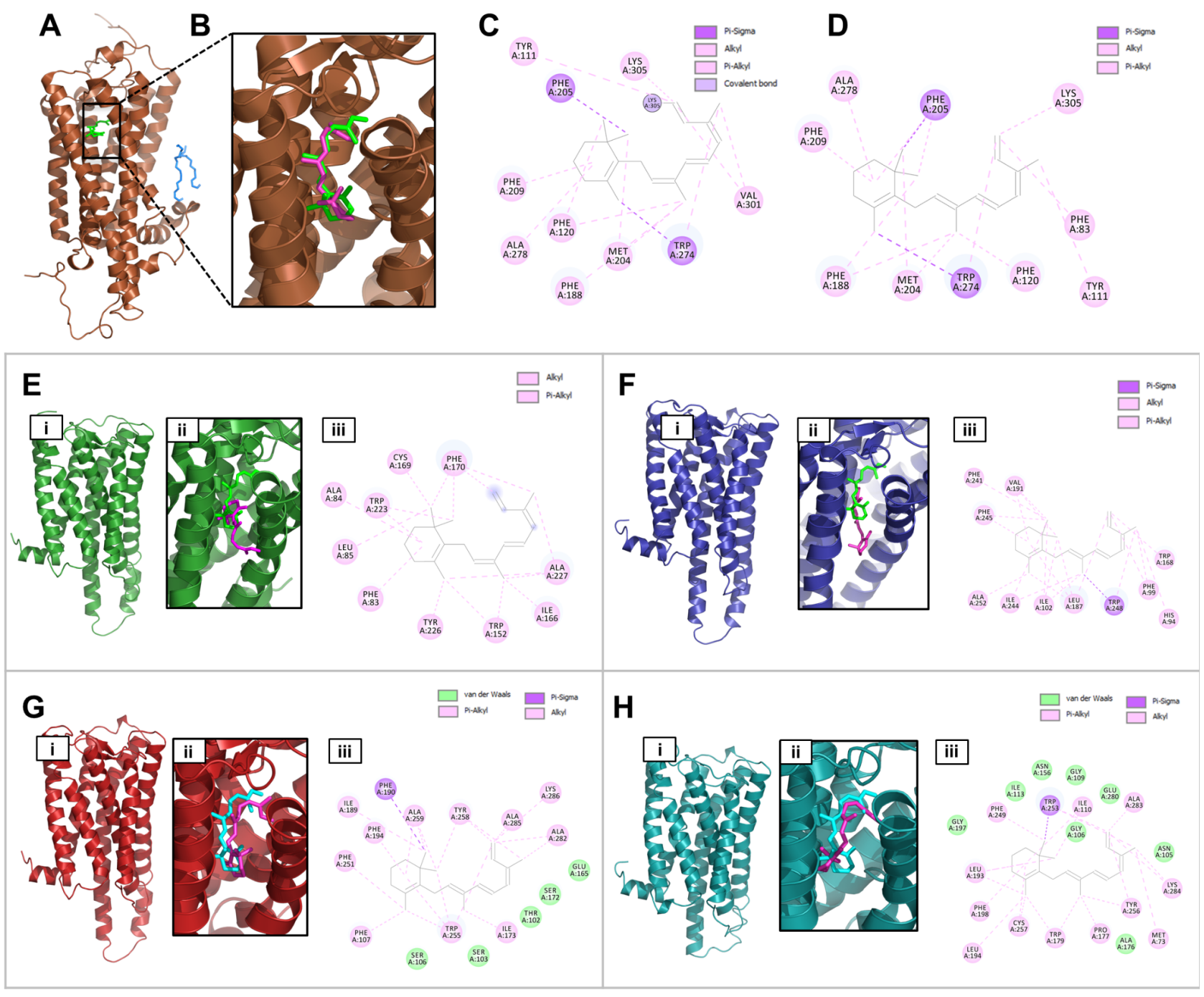

Figure 4. Homology modeling and molecular docking of rhodopsin receptors. (A) Crystal structure of squid rhodopsin (2ZIY). (B) Retinal in crystal structure and the docked conformation. (C, D) Molecular interactions of retinal in crystal structure vs. docked confirmation. (E, F, G, H) Homology modeling and docking studies with 629, 2270, and 19775, (i) homology model, (ii) retinal confirmations: natural (green) vs. docking pose (magenta), (iii) molecular interaction of docking pose (details of interactions and the docking scores are provided in supplementary table 2). 
bioRxiv preprint doi: https://doi.org/10.1101/2021.10.18.464760; this version posted October 28, 2021. The copyright holder for this preprint (which was not certified by peer review) is the author/funder, who has granted bioRxiv a license to display the preprint in perpetuity. It is made available under aCC-BY 4.0 International license.

\section{A \\ pdam_00014456-RA pdam_- $00011840-R A$ GNaT_1 HUMAN pdam_eoeor710-RA pdam_00011071-RA \\ pdam_00014456-RA pdam_00011840-RA pdam_e0017900-RA GNAT1_HUMAN pdam_00007710-RA pdam_e0011071-RA \\ pdam_00014456-RA pdam_00011840-RA pdam $00017900-R A$ GNAT1_HUMAN pdam_00007710-RA \\ pdam_00014456-RA pdam_00011840-RA pdam_e0017900-RA GNAT1_HUMAN pdam_-00007710-RA}

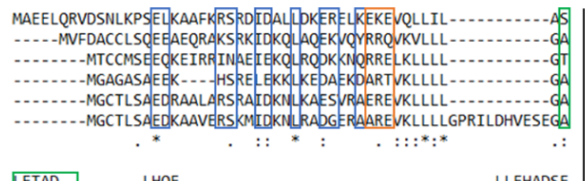

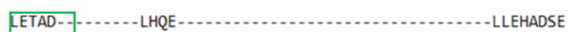
GESGKSTFLLKMRIIHGQDFDSEALNEFRPIIYANILKGMKVLADARRKLRLEWTDQSNQ GESGKSTFIKQMRIIHGQGYSDEDKLGWALVYQNVITAIQSLTLAMESLKIAYRNPANS GESGKSTIVKQMKIIHQDGYSLEECLEFIAIIYGNTLQSILAIVRAMTTLNIQYGDSARQ GESGKSTITVQMKIIHDHGFTAEDYSQYKPLVFSNAIYSLLKIIRAMDKLRIDFETDER GESGKSTIVKQMKIIHEHGYTQEECAQYRQWYSNTIQSMIAIIRALGTLKIEFGHGDRA

DSEMNMESLADR MYAERILAFTAPQQIOTELASYFDRRLWROKGIQNAYORRREFQLGDSSKYFLOHLE DDARKLMHMADTIEEGT MPKEMSDIIORLWKDSGIOACFERASEYOLNDSAGYYSDL MDAKMVEDWVARADDQEPFTPELTAAMKR LWDGGIKOCFRRSREYQLNDSARYYLDAIE DDARELFALAGSMEDVK-FTPELVSIMKRLWINDNGVONCFARSREYOLNDSAAYYLNALD **NGVQNCFARSREYQLNDSAAYYLNALD

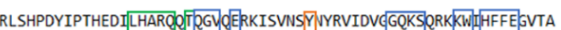
RIGRQDYMPSKQDVLHARKATKGIMEHEFIIKGIPFKMVDVGGQRSQRAKWFQCFDEVTS RLARPOYLPTEQDVLRARAP TSGI IEYPFDLETIIFRMVDVGGQRSERRKWIHCFENVTS RLVTPGYVPTEQDVLRSRVKI TGII IETQFSFKDL NFRMFDVGGQRSERKKWIIHCFEEVTC RIGAENYEPTAQDLLRTRVK IGIVEIQFDFKRLTFKLFDVGGQRS ERKMW H HCFEDVTA

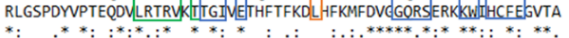

WFFVSLSSYDEFVEEDENSNAMHDSLELFEEISONAF/FEKTEFILFL NKHDLFVEKLKT ILFLVSSSAFDQVLMEDRTTNRLVESCNIFETIVINKKFFANVSIILFLNKTDLLMEKIKY

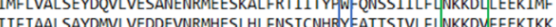
ITYCVA SAYDITLEDETTMPMEES KL FESIVINA U EVETSVILFL NKKD FFEKIKK IIFCVALSAYDIVLAEDEEMNRMMESMKLFDSICNNWWW TDTSIILFLNKKDL FAEKTTK

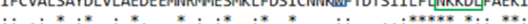

SNLSACFPDYDGGPD-PEIGLNYIRELFLSK--KPADKKHVYLHVTCATDTDLMKAVLKDV ANIKDYFPAFIGDQRKLEDVQNFILQMFDSKR-REFSKALFHHFTTAIDTENIKFVFHAV SHLVEYFPEFDGPQCDAQAAREFILKMFVDLN-PDSLKIIIYSHFTCATDTENIRFVFAAV AHLSICFPDYDGPNT -YEDAGNYIKVQFLELNMRRDYKEIYSHMTCATDTONVKFVFDAV SPLTICFPDYSGPNT -YEAGCLYIRKQFEAKN-LNDEKEIYNHLTCATDTDNITFVFNAV SPLTICFPEYTGSNT YEEAAAYIQLQFENLNKRKDIKEIYYTHFICATDTNNIQFVFDAV

\section{FEILVDINLKKLSTL Rhodopsin \\ KDTILOLNLKEYNLY}

DPTIKENLKDCGL

TPTINIKGCGLY

DVIIKNNLKDCGL

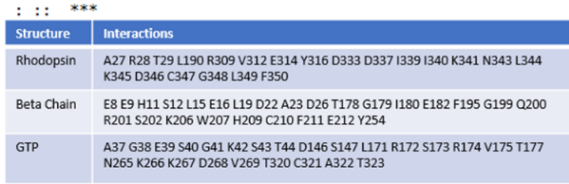

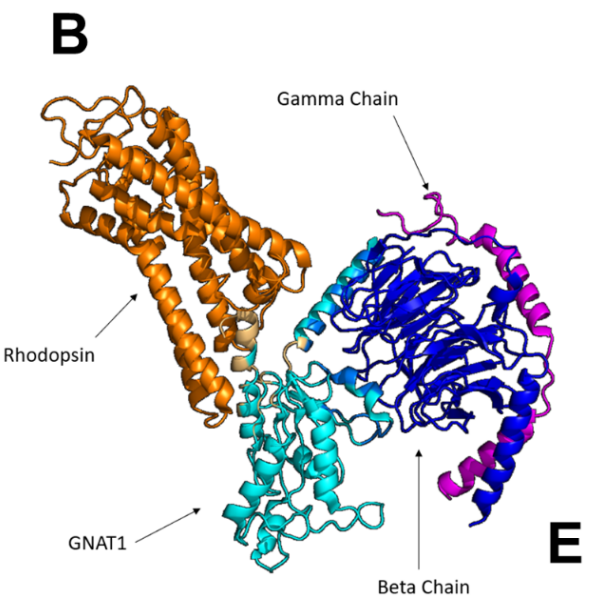
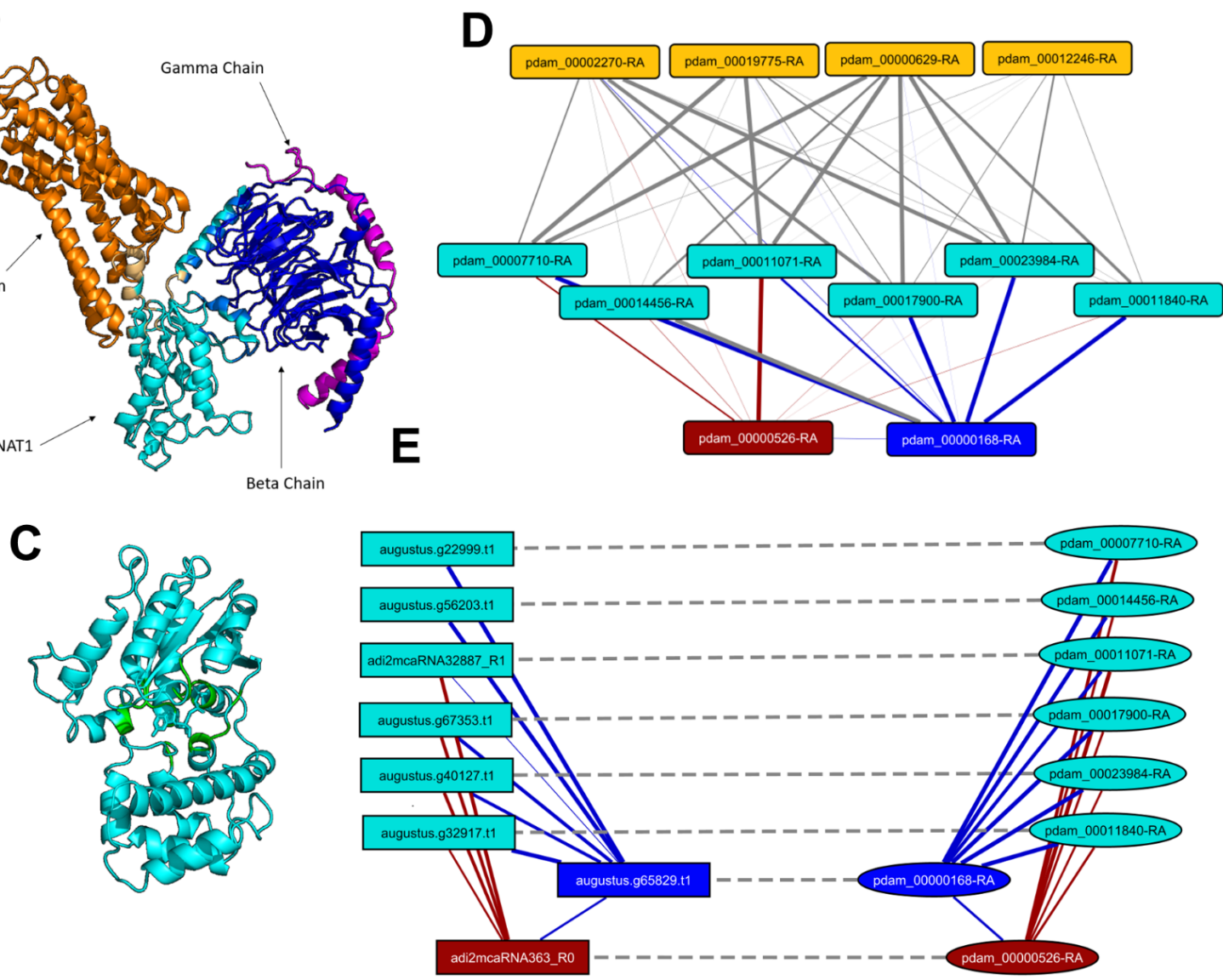

Cyan $=$ Alpha, Blue $=$ Beta, Red $=$ Gamma, Orange $=$ Rhodopsin

Figure 5. (A) MSA of GNAT1 with coral homologues and crystal structures of GNAT1. Amino acids of GNAT1 which interact with rhodopsin, GNB1 (beta chain), and GTP are boxed in blue, red, and green, respectively. The same amino acids are also listed in the table. In the crystal structures, GNAT1 (cyan) binding interfaces with rhodopsin (orange) and the beta chain (blue) are shown in (B) and the GTP binding pocket (green) is shown in (C). (D) Predicted interactions 
in $P$. damicornis between alpha (cyan), beta (blue), gamma (orange) chains and rhodopsin (orange). (E) Predicted candidate $G$ protein interactions in $P$. damicornis, and the predicted interactions of the corresponding candidates in $M$. capitata (solid line: predicted interaction; dashed line: best-bidirectional BLAST hit).

A

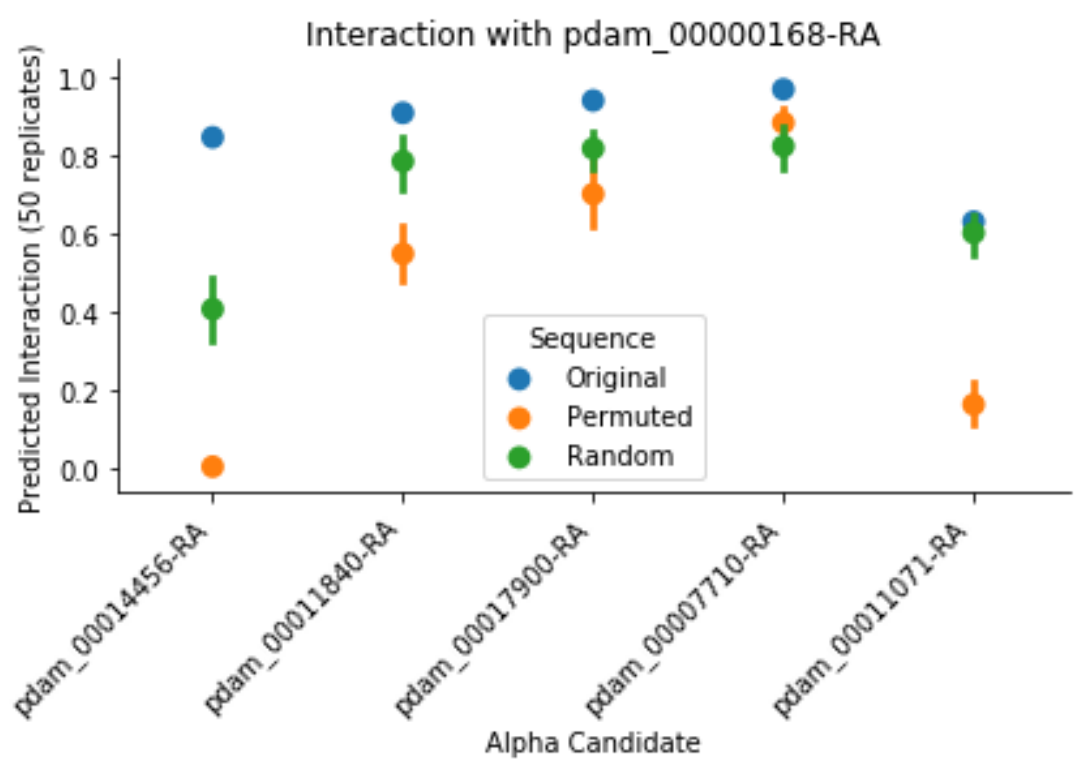

B

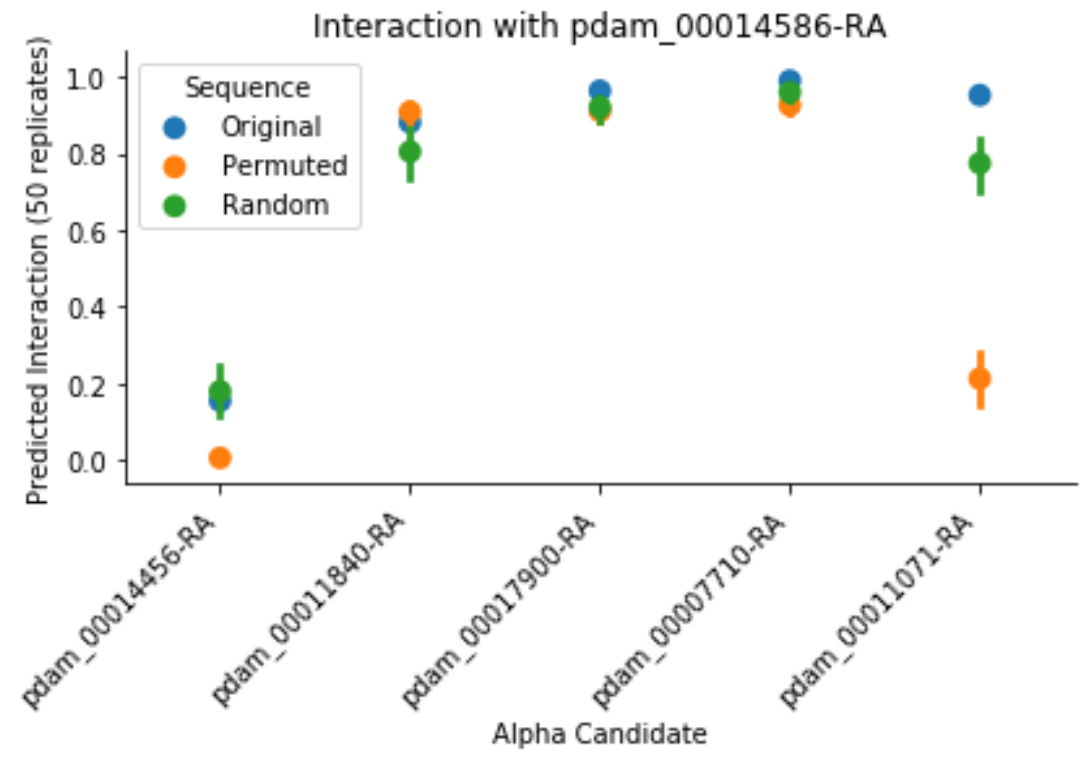

Figure 6. Predicted interaction of candidate alpha proteins with beta candidate proteins pdam_00000168-RA (A), pdam_00014586-RA (B). Original: Original predicted probability. 
bioRxiv preprint doi: https://doi.org/10.1101/2021.10.18.464760; this version posted October 28, 2021. The copyright holder for this preprint

(which was not certified by peer review) is the author/funder, who has granted bioRxiv a license to display the preprint in perpetuity. It is made available under aCC-BY 4.0 International license.

Permuted: Average predicted probability of 50 samples with 25 beta-binding residues randomly perturbed. Random: Average predicted probability of 50 samples with 25 randomly chosen residues randomly perturbed. 


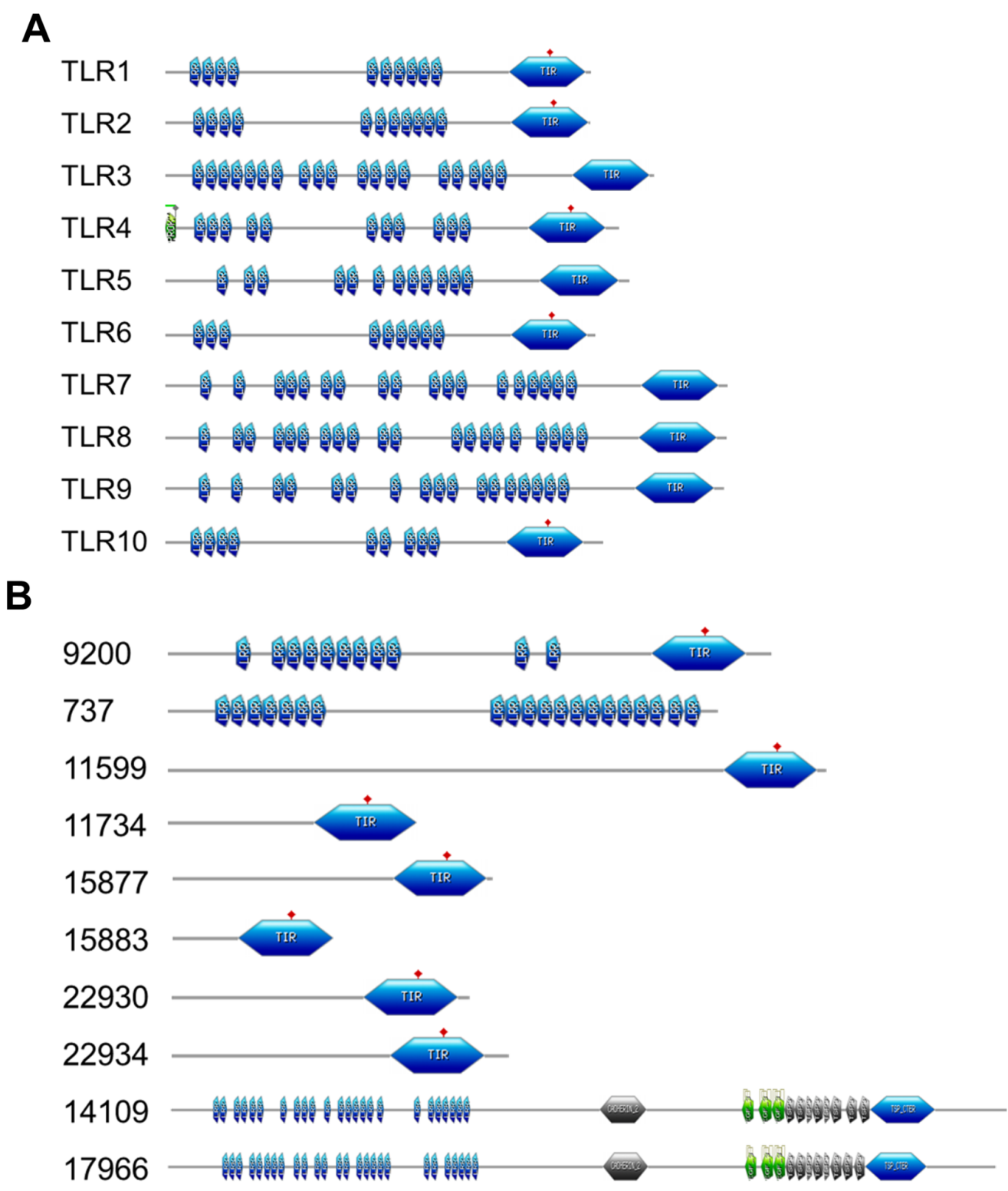

Figure 7. PROSITE analysis of human and coral TLRs. (A) PROSITE domain mapping of human TLRs (B) domain mapping of possible $P$. damicornis TLRs homologues. 

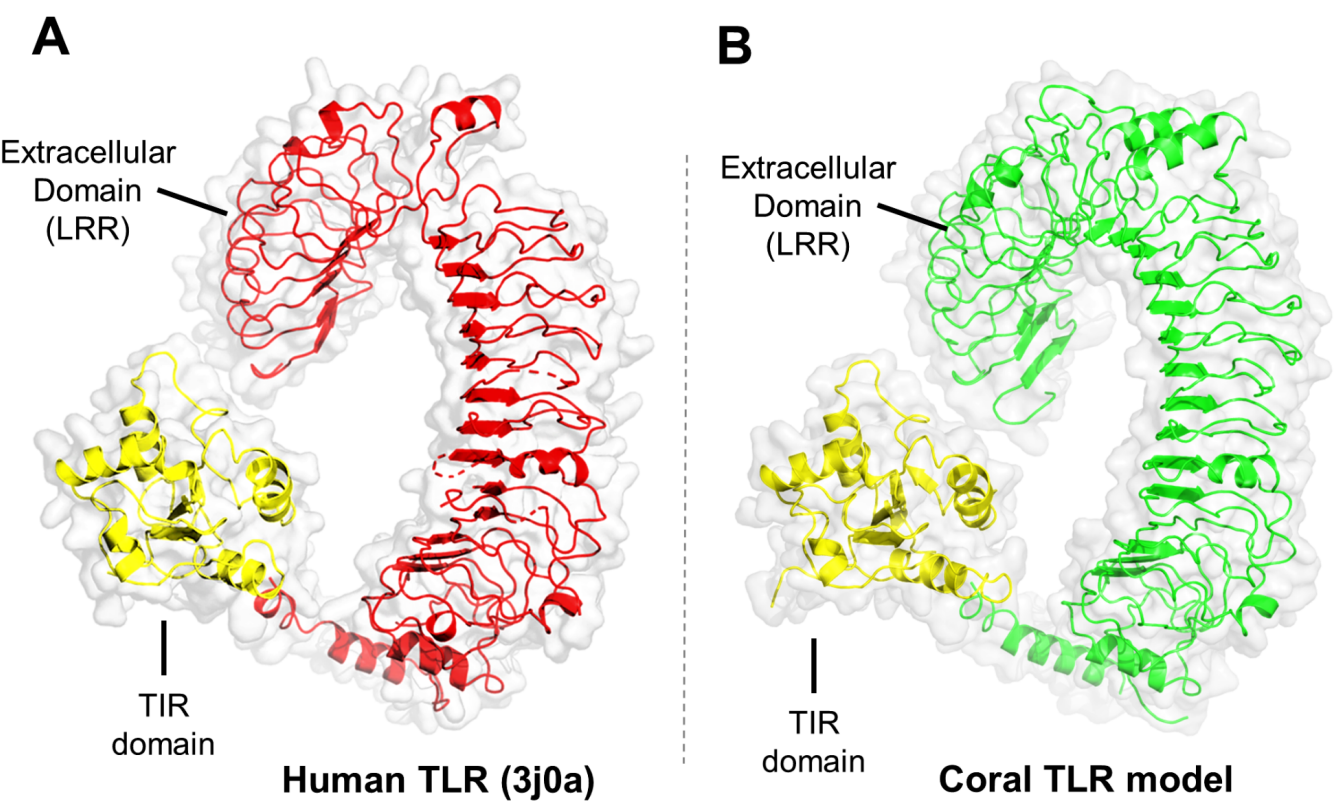

Figure 8. Coral TLR model construction using full-length TLR5 homology model structure. (LRR: leucine rich repeats). (A) homology model of full-length human TLR5 protein (3j0a) (B) model of $P$. damicornis 9200 protein using human TLR5 homology model as a template. 
Table 1. Number of times a model organism shows homology to a given $P$. damicornis protein with $100 \%$ probability. Columns highlighted in green show at least one representation in each model organism studied.

\begin{tabular}{|c|c|c|c|c|c|c|c|c|c|c|c|c|c|}
\hline \multirow[t]{2}{*}{ Organisms } & \multicolumn{13}{|c|}{ P. damicornis proteins } \\
\hline & 22934 & 22930 & 11599 & 9200 & 14109 & 17966 & 13021 & 15883 & 11734 & 21819 & 737 & 15877 & 9057 \\
\hline Human & 5 & 5 & 10 & 7 & 4 & 3 & 3 & 2 & 2 & 2 & 1 & 1 & - \\
\hline Zebrafish & 8 & 7 & 11 & 9 & 6 & 6 & 2 & - & - & 2 & 1 & - & - \\
\hline Frog & 6 & 5 & 10 & 10 & 4 & 4 & 3 & - & - & - & - & - & 1 \\
\hline Chicken & 7 & 7 & 9 & 9 & 2 & 2 & 1 & - & - & - & - & 1 & - \\
\hline Drosophila & 9 & 9 & 7 & 9 & 2 & 3 & 2 & - & - & 1 & - & 1 & - \\
\hline
\end{tabular}


bioRxiv preprint doi: https://doi.org/10.1101/2021.10.18.464760; this version posted October 28, 2021. The copyright holder for this preprint (which was not certified by peer review) is the author/funder, who has granted bioRxiv a license to display the preprint in perpetuity. It is made available under aCC-BY 4.0 International license.

\section{Supplementary Figures and Tables:}

Figure S1. Clustal omega multiple sequence alignment of opsin homologs. Residues involved in active site formation are highlighted in blue.

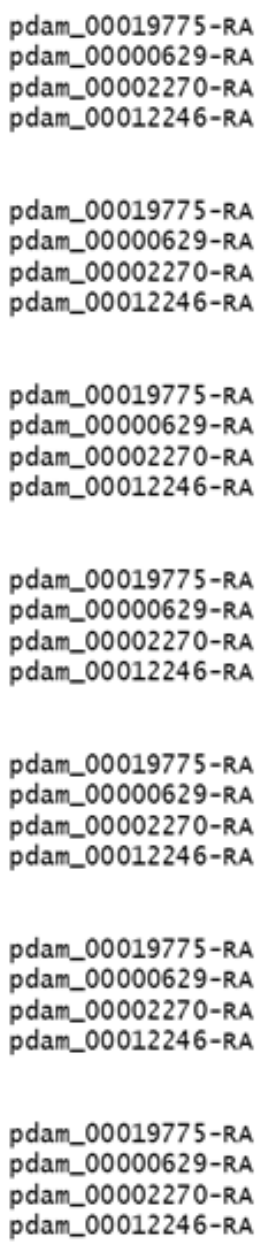

pdam_00019775-RA pdam_00000629-RA pdam_00002270-RA pdam_00012246-RA

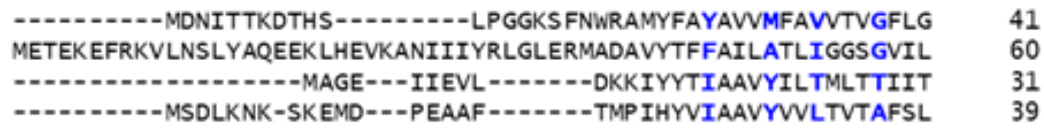

NVLTLIILHYREHR--KKVLTPLMINLAVGDILMVIVVYPVVIASNLVGKQLKEGSLRCK NFL--VCLMYFATPKLLDATNIFMLNMAVGDLTYSIVALPLLVASNARGE-WAFGEAGCT NSI --VILTFYKVRCLLTPSSLPILSLAMADLVLAVTVMPFGIVANANRI -WLVGDFGCH NTL--VIWAFVKDRTLRTRSNSLILSIAVGDWLHAVLAYPLGVVKNASQS-WRLSGGACT

WSAFANGAIGITTIATLTVMSGVMYHGIKQTLPK--PKIHAKNMSLLVLSTWLYGI FLNL AYAFITFFFALGTMMLLAVAAYERYFTLCRLYNDGQTQFSKKRAIVLCALIWCYSLFWSV WYAYGHTVVGFSSILHHGVIAVEAARKIVRGLRN--AGARRRGMITTIVVVWAVVLVWGT WYAFITSFLSFGIMLHYATFSIERAITINFSEAL---FCIERKLGLIIAGLWLFALLWSS

PPVIGWTRAVPGEAGISCAP EWTSSEPESVAYIAFLLVFGFFLPLTVIGTFHYMIYRVIR MPVLGWSRYIPEGIGTSCSVDWTSKEQGNWWFTILLILGCFLLPVSIIICSYLKTFRALR MPLIGWSSYGPEGSGAVCSINWKSTDPTDVSFVMITFVLFLFIPVIIIMACYTAISYDLR FPLFGWSAYVPEGAGVCCSIRWQSSDPLDITFVACIFLFFFFGPVVTMVIAYYSVYNNMK

RVPLEGNP-----MIRACRMKSKMRLVRMTSFSIAAFVVSWLPYCVVSIAALVNGHHVL 271 KLSQQALQNWGENNRVTQETLKAESKMMWIIIAITAGYLFAWTPYALTAVVAII-NPNRI 296 RMARIAEKQWGRKAQMTIARVLAKKKSMWTGLIMFVAIFFVWMPYAIISFLSVIGTPEKI 266 KMTLNAHGLWGENAAPTMEVIQAEGKIGRMAFMMSTCFLFAWTPYAVVSLYAIINQPEDI 273

SSGEAEIPELMAKASVIYNPFVYAFTNGTYRASLKGLLIGGNSVIRVNPSVLRTSPAPSS SPIGATIPAYMAKSSACYNPIIYVFMYRKMRSRLWAILCCKKSQVHPDAQIAS--EM-AS PPLAFALAAMFAKTSTFVNPLICFFWYHKFRDGTKRIYKNSKRMASLQKAWTT-...-.. TPLVATLPALFAKTAPCYNPVIYFLSYKKFRESLKRTLRRQGNTSAVSRL-........- 
Supplementary Table S1. The details of residues and their molecular interactions with the retinal active site in squid rhodopsin and coral putative rhodopsin proteins.

\begin{tabular}{|c|c|c|c|c|c|c|}
\hline Protein & Ligand & $\begin{array}{c}\text { Covalent } \\
\text { bond }\end{array}$ & Pi-Sigma & Alkyl and Pi-Alkyl & $\begin{array}{l}\text { Van der } \\
\text { Waals }\end{array}$ & $\begin{array}{c}\text { Score } \\
\mathrm{kcal} / \mathrm{mol}\end{array}$ \\
\hline $\begin{array}{c}\text { Squid } \\
\text { Rhodopsi } \\
\text { n (2ziy) }\end{array}$ & Retinal & Lys 305 & $\begin{array}{c}\text { Phe205, } \\
\text { Trp274 }\end{array}$ & $\begin{array}{l}\text { Tyr 111, Val 301, } \\
\text { Met204, Phe188, } \\
\text { Phe120, Ala278, } \\
\text { Phe209 }\end{array}$ & - & \\
\hline $\begin{array}{c}\text { Squid } \\
\text { Rhodopsi } \\
n \\
\text { (2ziy) }\end{array}$ & Retinal & -- & $\begin{array}{l}\text { Phe205, } \\
\text { Trp274 }\end{array}$ & $\begin{array}{l}\text { Lys305, Tyr111, } \\
\text { Met204, Phe188, } \\
\text { Phe120, Ala278, } \\
\text { Phe209 }\end{array}$ & - & -10.9 \\
\hline $\begin{array}{c}629 \\
\text { Model }\end{array}$ & Retinal & -- & -- & $\begin{array}{c}\text { Ala84, Trp223, } \\
\text { Cys169, Phe170, } \\
\text { Ala227, lle166, Trp152, } \\
\text { Tyr226, Phe83, Leu85 }\end{array}$ & - & -7.6 \\
\hline $\begin{array}{c}\text { Model } \\
2270\end{array}$ & Retinal & -- & Trp248 & $\begin{array}{c}\text { Phe241, Val191, } \\
\text { Phe245, Ala252, } \\
\text { Ile244, Ile102, Leu187, } \\
\text { Phe99, His94 }\end{array}$ & - & -8.4 \\
\hline $\begin{array}{l}\text { Model } \\
12246\end{array}$ & Retinal & -- & Phe190 & $\begin{array}{c}\text { Phe251, Phe194, } \\
\text { Ile189, Ala259, Tyr258, } \\
\text { Ala285, Lys286, } \\
\text { Ala282, Ile173, Trp255, } \\
\text { Phe107 }\end{array}$ & - & -8.8 \\
\hline $\begin{array}{l}\text { Model } \\
19775\end{array}$ & Retinal & -- & Trp253 & $\begin{array}{l}\text { Phe249, Ile110, } \\
\text { Ala283, Lys284, } \\
\text { Met73, Tyr256, } \\
\text { Pro177, Trp179, } \\
\text { Cys257, Leu194, } \\
\text { Phe198, Leu193 }\end{array}$ & $\begin{array}{l}\text { Gly197, } \\
\text { Ile113, } \\
\text { Asn156, } \\
\text { Gly109, } \\
\text { Glu280, } \\
\text { Gly106, } \\
\text { Asn105, } \\
\text { Ala176 }\end{array}$ & -7.0 \\
\hline
\end{tabular}




\section{References}

Akira, S., \& Takeda, K. (2004). Toll-like receptor signalling. Nature Reviews. Immunology, 4(7), 499-511.

Allen, A. S., Seymour, A. C., \& Rittschof, D. (2017). Chemoreception drives plastic consumption in a hard coral. In Marine Pollution Bulletin (Vol. 124, Issue 1, pp. 198-205). https://doi.org/10.1016/j.marpolbul.2017.07.030

Almén, M. S., Nordström, K. J. V., Fredriksson, R., \& Schiöth, H. B. (2009). Mapping the human membrane proteome: a majority of the human membrane proteins can be classified according to function and evolutionary origin. BMC Biology, 7, 50.

Altschul, S. F., Madden, T. L., Schäffer, A. A., Zhang, J., Zhang, Z., Miller, W., \& Lipman, D. J. (1997). Gapped BLAST and PSI-BLAST: a new generation of protein database search programs. Nucleic Acids Research, 25(17), 3389-3402.

Anderson, D. A., Walz, M. E., Weil, E., Tonellato, P., \& Smith, M. C. (2016). RNA-Seq of the Caribbean reef-building coral Orbicella faveolata (Scleractinia-Merulinidae) under bleaching and disease stress expands models of coral innate immunity. PeerJ, 4, e1616.

Balakrishnan, S., Kamisetty, H., Carbonell, J. G., Lee, S.-I., \& Langmead, C. J. (2011). Learning generative models for protein fold families. Proteins, 79(4), 1061-1078.

Ben-Shlomo, I., Yu Hsu, S., Rauch, R., Kowalski, H. W., \& Hsueh, A. J. W. (2003). Signaling receptome: a genomic and evolutionary perspective of plasma membrane receptors involved in signal transduction. Science's STKE: Signal Transduction Knowledge Environment, 2003(187), RE9.

Campbell, M. S., Holt, C., Moore, B., \& Yandell, M. (2014). Genome Annotation and Curation Using MAKER and MAKER-P. Current Protocols in Bioinformatics / Editoral Board, Andreas D. Baxevanis ... [et Al.], 48, 4.11.1-39. 
Capra, J. A., \& Singh, M. (2007). Predicting functionally important residues from sequence conservation. Bioinformatics , 23(15), 1875-1882.

Chapman, J. A., Kirkness, E. F., Simakov, O., Hampson, S. E., Mitros, T., Weinmaier, T., Rattei, T., Balasubramanian, P. G., Borman, J., Busam, D., Disbennett, K., Pfannkoch, C., Sumin, N., Sutton, G. G., Viswanathan, L. D., Walenz, B., Goodstein, D. M., Hellsten, U., Kawashima, T., ... Steele, R. E. (2010). The dynamic genome of Hydra. Nature, 464(7288), 592-596.

Chen, H., \& Jiang, Z. (2013). The essential adaptors of innate immune signaling. Protein \& Cell, 4(1), 27-39.

Copper, P. (2001). Evolution, Radiations, and Extinctions in Proterozoic to Mid-Paleozoic Reefs. In Topics in Geobiology (pp. 89-119). https://doi.org/10.1007/978-1-4615-1219-6_3

Cunning, R., Bay, R. A., Gillette, P., Baker, A. C., \& Traylor-Knowles, N. (2018). Comparative analysis of the Pocillopora damicornis genome highlights role of immune system in coral evolution. Scientific Reports, 8(1), 16134.

de Castro, E., Sigrist, C. J. A., Gattiker, A., Bulliard, V., Langendijk-Genevaux, P. S., Gasteiger, E., Bairoch, A., \& Hulo, N. (2006). ScanProsite: detection of PROSITE signature matches and ProRule-associated functional and structural residues in proteins. Nucleic Acids Research, 34(Web Server issue), W362-W365.

de Mendoza, A., Sebé-Pedrós, A., \& Ruiz-Trillo, I. (2014). The evolution of the GPCR signaling system in eukaryotes: modularity, conservation, and the transition to metazoan multicellularity. Genome Biology and Evolution, 6(3), 606-619.

Dong, W., Liu, Y., Peng, J., Chen, L., Zou, T., Xiao, H., Liu, Z., Li, W., Bu, Y., \& Qi, Y. (2006). The IRAK-1-BCL10-MALT1-TRAF6-TAK1 Cascade Mediates Signaling to NF-KB from Toll-like Receptor 4. In Journal of Biological Chemistry (Vol. 281, Issue 36, pp. 26029-26040). https://doi.org/10.1074/jbc.m513057200

Dunne, A., \& O'Neill, L. A. J. (2005). Adaptor usage and Toll-like receptor signaling specificity. 
FEBS Letters, 579(15), 3330-3335.

Eddy, S. R. (1998). Profile hidden Markov models. Bioinformatics , 14(9), 755-763.

Edgar, R. C. (2004). MUSCLE: multiple sequence alignment with high accuracy and high throughput. Nucleic Acids Research, 32(5), 1792-1797.

Ekblom, R., \& Wolf, J. B. W. (2014). A field guide to whole-genome sequencing, assembly and annotation. Evolutionary Applications, 7(9), 1026-1042.

Foster, T., \& Gilmour, J. P. (2016). Seeing red: Coral larvae are attracted to healthy-looking reefs. In Marine Ecology Progress Series (Vol. 559, pp. 65-71).

https://doi.org/10.3354/meps 11902

Hake, K. H. (2019). The microbiome of a colonial choanoflagellate from Mono Lake, CA. University of California, Berkeley.

Harris, R., Olson, A. J., \& Goodsell, D. S. (2008). Automated prediction of ligand-binding sites in proteins. Proteins, 70(4), 1506-1517.

Hughes, T. P., Kerry, J. T., Baird, A. H., Connolly, S. R., Dietzel, A., Eakin, C. M., Heron, S. F., Hoey, A. S., Hoogenboom, M. O., Liu, G., McWilliam, M. J., Pears, R. J., Pratchett, M. S., Skirving, W. J., Stella, J. S., \& Torda, G. (2018). Global warming transforms coral reef assemblages. Nature, 556(7702), 492-496.

Imler, J. L., \& Hoffmann, J. A. (2002). Toll receptors in Drosophila: a family of molecules regulating development and immunity. Current Topics in Microbiology and Immunology, $270,63-79$.

Ishii, A., Kawasaki, M., Matsumoto, M., Tochinai, S., \& Seya, T. (2007). Phylogenetic and expression analysis of amphibian Xenopus Toll-like receptors. Immunogenetics, 59(4), 281-293.

Jékely, G. (2013). Global view of the evolution and diversity of metazoan neuropeptide signaling. Proceedings of the National Academy of Sciences of the United States of America, 110(21), 8702-8707. 
Jumper, J., Evans, R., Pritzel, A., Green, T., Figurnov, M., Ronneberger, O., Tunyasuvunakool, K., Bates, R., Žídek, A., Potapenko, A., Bridgland, A., Meyer, C., Kohl, S. A. A., Ballard, A. J., Cowie, A., Romera-Paredes, B., Nikolov, S., Jain, R., Adler, J., ... Hassabis, D. (2021). Highly accurate protein structure prediction with AlphaFold. Nature, 596(7873), 583-589.

Kalinina, O. V., Mironov, A. A., Gelfand, M. S., \& Rakhmaninova, A. B. (2004). Automated selection of positions determining functional specificity of proteins by comparative analysis of orthologous groups in protein families. Protein Science: A Publication of the Protein Society, 13(2), 443-456.

Kang, J. Y., Nan, X., Jin, M. S., Youn, S.-J., Ryu, Y. H., Mah, S., Han, S. H., Lee, H., Paik, S.-G., \& Lee, J.-O. (2009). Recognition of lipopeptide patterns by Toll-like receptor 2-Toll-like receptor 6 heterodimer. Immunity, 31(6), 873-884.

Kanwal, Z., Wiegertjes, G. F., Veneman, W. J., Meijer, A. H., \& Spaink, H. P. (2014).

Comparative studies of Toll-like receptor signalling using zebrafish. Developmental and Comparative Immunology, 46(1), 35-52.

Karplus, K., Barrett, C., \& Hughey, R. (1998). Hidden Markov models for detecting remote protein homologies. Bioinformatics , 14(10), 846-856.

Kortschak, R. D., Samuel, G., Saint, R., \& Miller, D. J. (2003). EST analysis of the cnidarian Acropora millepora reveals extensive gene loss and rapid sequence divergence in the model invertebrates. Current Biology: CB, 13(24), 2190-2195.

Krishnan, A., Dnyansagar, R., Almén, M. S., Williams, M. J., Fredriksson, R., Manoj, N., \& Schiöth, H. B. (2014). The GPCR repertoire in the demosponge Amphimedon queenslandica: insights into the GPCR system at the early divergence of animals. BMC Evolutionary Biology, 14, 270.

LaJeunesse, T. C., Parkinson, J. E., Gabrielson, P. W., Jeong, H. J., Reimer, J. D., Voolstra, C. R., \& Santos, S. R. (2018). Systematic Revision of Symbiodiniaceae Highlights the Antiquity and Diversity of Coral Endosymbionts. Current Biology: CB, 28(16), 2570-2580.e6. 
Levy, O., Dubinsky, Z., \& Achituv, Y. (2003). Photobehavior of stony corals: responses to light spectra and intensity. The Journal of Experimental Biology, 206(Pt 22), 4041-4049.

Liu, H., Stephens, T. G., González-Pech, R. A., Beltran, V. H., Lapeyre, B., Bongaerts, P., Cooke, I., Aranda, M., Voolstra, C., \& Chan, C. X. (2018). Symbiodinium Genomes Reveal Adaptive Evolution of Functions Related to Coral-dinoflagellate Symbiosis.

Mansfield, K. M., \& Gilmore, T. D. (2019). Innate immunity and cnidarian-Symbiodiniaceae mutualism. Developmental and Comparative Immunology, 90, 199-209.

Mason, B., Beard, M., \& Miller, M. W. (2011). Coral larvae settle at a higher frequency on red surfaces. In Coral Reefs (Vol. 30, Issue 3, pp. 667-676). https://doi.org/10.1007/s00338-011-0739-1

Miller, D. J., Hemmrich, G., Ball, E. E., Hayward, D. C., Khalturin, K., Funayama, N., Agata, K., \& Bosch, T. C. G. (2007). The innate immune repertoire in cnidaria--ancestral complexity and stochastic gene loss. Genome Biology, 8(4), R59.

Moitra, S., Tirupula, K. C., Klein-Seetharaman, J., \& Langmead, C. J. (2012). A minimal ligand binding pocket within a network of correlated mutations identified by multiple sequence and structural analysis of G protein coupled receptors. BMC Biophysics, 5, 13.

Narayanan, K. B., \& Park, H. H. (2015). Toll/interleukin-1 receptor (TIR) domain-mediated cellular signaling pathways. Apoptosis: An International Journal on Programmed Cell Death, 20(2), 196-209.

Nawab, A., An, L., Wu, J., Li, G., Liu, W., Zhao, Y., Wu, Q., \& Xiao, M. (2019). Chicken toll-like receptors and their significance in immune response and disease resistance. International Reviews of Immunology, 38(6), 284-306.

Nemecz, Á., Prevost, M. S., Menny, A., \& Corringer, P.-J. (2016). Emerging Molecular Mechanisms of Signal Transduction in Pentameric Ligand-Gated lon Channels. Neuron, $90(3), 452-470$.

Nordström, K. J. V., Sällman Almén, M., Edstam, M. M., Fredriksson, R., \& Schiöth, H. B. 
(2011). Independent HHsearch, Needleman-Wunsch-Based, and Motif Analyses Reveal the Overall Hierarchy for Most of the G Protein-Coupled Receptor Families. Molecular Biology and Evolution, 28(9), 2471-2480.

Nyholm, S. V., \& Graf, J. (2012). Knowing your friends: invertebrate innate immunity fosters beneficial bacterial symbioses. Nature Reviews. Microbiology, 10(12), 815-827.

Ohto, U., Ishida, H., Shibata, T., Sato, R., Miyake, K., \& Shimizu, T. (2018). Toll-like Receptor 9 Contains Two DNA Binding Sites that Function Cooperatively to Promote Receptor Dimerization and Activation. Immunity, 48(4), 649-658.e4.

Oprea, T. I. (2019). Exploring the dark genome: implications for precision medicine. Mammalian Genome: Official Journal of the International Mammalian Genome Society, 30(7-8), 192-200.

Park, B. S., Song, D. H., Kim, H. M., Choi, B.-S., Lee, H., \& Lee, J.-O. (2009). The structural basis of lipopolysaccharide recognition by the TLR4-MD-2 complex. Nature, 458(7242), $1191-1195$.

Pearson, W. R. (1991). Searching protein sequence libraries: comparison of the sensitivity and selectivity of the Smith-Waterman and FASTA algorithms. Genomics, 11(3), 635-650.

Remmert, M., Biegert, A., Hauser, A., \& Söding, J. (2011). HHblits: lightning-fast iterative protein sequence searching by HMM-HMM alignment. Nature Methods, 9(2), 173-175.

Rost, B. (1999). Twilight zone of protein sequence alignments. Protein Engineering, 12(2), 85-94.

Sakmar, T. P. (2010). Structure and Function of G-Protein-Coupled Receptors. In Handbook of Cell Signaling (pp. 151-156). https://doi.org/10.1016/b978-0-12-374145-5.00023-1

Schiöth, H. B., Nordström, K. J. V., \& Fredriksson, R. (2010). The adhesion GPCRs; gene repertoire, phylogeny and evolution. Advances in Experimental Medicine and Biology, 706, $1-13$.

Shimamura, T., Hiraki, K., Takahashi, N., Hori, T., Ago, H., Masuda, K., Takio, K., Ishiguro, M., \& 
Miyano, M. (2008). Crystal structure of squid rhodopsin with intracellularly extended cytoplasmic region. The Journal of Biological Chemistry, 283(26), 17753-17756.

Shumaker, A., Putnam, H. M., Qiu, H., Price, D. C., Zelzion, E., Harel, A., Wagner, N. E., Gates, R. D., Yoon, H. S., \& Bhattacharya, D. (2019). Genome analysis of the rice coral Montipora capitata. Scientific Reports, 9(1), 2571.

Sledzieski, S., Singh, R., Cowen, L., \& Berger, B. (2021). D-SCRIPT translates genome to phenome with sequence-based, structure-aware, genome-scale predictions of protein-protein interactions. Cell Systems. https://doi.org/10.1016/j.cels.2021.08.010

Smith, T. F., \& Waterman, M. S. (1981). Identification of common molecular subsequences. Journal of Molecular Biology, 147(1), 195-197.

Söding, J., Biegert, A., \& Lupas, A. N. (2005). The HHpred interactive server for protein homology detection and structure prediction. Nucleic Acids Research, 33(Web Server issue), W244-W248.

Song, W. S., Jeon, Y. J., Namgung, B., Hong, M., \& Yoon, S.-I. (2017). A conserved TLR5 binding and activation hot spot on flagellin. Scientific Reports, 7, 40878.

Song, W., Wang, J., Han, Z., Zhang, Y., Zhang, H., Wang, W., Chang, J., Xia, B., Fan, S., Zhang, D., Wang, J., Wang, H.-W., \& Chai, J. (2015). Structural basis for specific recognition of single-stranded RNA by Toll-like receptor 13. Nature Structural \& Molecular Biology, 22(10), 782-787.

Sriram, K., \& Insel, P. A. (2018). G Protein-Coupled Receptors as Targets for Approved Drugs: How Many Targets and How Many Drugs? In Molecular Pharmacology (Vol. 93, Issue 4, pp. 251-258). https://doi.org/10.1124/mol.117.111062

Srivastava, M., Begovic, E., Chapman, J., Putnam, N. H., Hellsten, U., Kawashima, T., Kuo, A., Mitros, T., Salamov, A., Carpenter, M. L., Signorovitch, A. Y., Moreno, M. A., Kamm, K., Grimwood, J., Schmutz, J., Shapiro, H., Grigoriev, I. V., Buss, L. W., Schierwater, B., ... Rokhsar, D. S. (2008). The Trichoplax genome and the nature of placozoans. Nature, 
454(7207), 955-960.

Surgand, J.-S., Rodrigo, J., Kellenberger, E., \& Rognan, D. (2006). A chemogenomic analysis of the transmembrane binding cavity of human G-protein-coupled receptors. Proteins, 62(2), 509-538.

Tang, J., Xu, L., Zeng, Y., \& Gong, F. (2021). Effect of gut microbiota on LPS-induced acute lung injury by regulating the TLR4/NF-kB signaling pathway. International Immunopharmacology, $91,107272$.

Thompson, J. R., Rivera, H. E., Closek, C. J., \& Medina, M. (2014). Microbes in the coral holobiont: partners through evolution, development, and ecological interactions. Frontiers in Cellular and Infection Microbiology, 4, 176.

Valanne, S., Wang, J.-H., \& Rämet, M. (2011). The Drosophila Toll Signaling Pathway. In The Journal of Immunology (Vol. 186, Issue 2, pp. 649-656).

https://doi.org/10.4049/jimmunol.1002302

van Oppen, M. J. H., \& Blackall, L. L. (2019). Coral microbiome dynamics, functions and design in a changing world. In Nature Reviews Microbiology (Vol. 17, Issue 9, pp. 557-567). https://doi.org/10.1038/s41579-019-0223-4

Vidal-Dupiol, J., Ladrière, O., Meistertzheim, A.-L., Fouré, L., Adjeroud, M., \& Mitta, G. (2011). Physiological responses of the scleractinian coral Pocillopora damicornis to bacterial stress from Vibrio coralliilyticus. In Journal of Experimental Biology (Vol. 214, Issue 9, pp. 1533-1545). https://doi.org/10.1242/jeb.053165

Viterbi, A. J. (2009). Error Bounds for Convolutional Codes and an Asymptotically Optimum Decoding Algorithm. In The Foundations of the Digital Wireless World (pp. 41-50). https://doi.org/10.1142/9789814287517_0004

Waterhouse, A., Bertoni, M., Bienert, S., Studer, G., Tauriello, G., Gumienny, R., Heer, F. T., de Beer, T. A. P., Rempfer, C., Bordoli, L., Lepore, R., \& Schwede, T. (2018). SWISS-MODEL: homology modelling of protein structures and complexes. Nucleic Acids Research, 46(W1), 
W296-W303.

Weiss, Y., Forêt, S., Hayward, D. C., Ainsworth, T., King, R., Ball, E. E., \& Miller, D. J. (2013).

The acute transcriptional response of the coral Acropora millepora to immune challenge:

expression of GiMAP/IAN genes links the innate immune responses of corals with those of mammals and plants. BMC Genomics, 14, 400.

Wettschureck, N., \& Offermanns, S. (2005). Mammalian G proteins and their cell type specific functions. Physiological Reviews, 85(4), 1159-1204.

Williams, L. M., Fuess, L. E., Brennan, J. J., Mansfield, K. M., Salas-Rodriguez, E., Welsh, J., Awtry, J., Banic, S., Chacko, C., Chezian, A., Dowers, D., Estrada, F., Hsieh, Y.-H., Kang, J., Li, W., Malchiodi, Z., Malinowski, J., Matuszak, S., McTigue, T., 4th, ... Gilmore, T. D. (2018). A conserved Toll-like receptor-to-NF-kB signaling pathway in the endangered coral Orbicella faveolata. Developmental and Comparative Immunology, 79, 128-136.

Wooldridge, S. A. (2010). Is the coral-algae symbiosis really "mutually beneficial" for the partners? In BioEssays (Vol. 32, Issue 7, pp. 615-625).

https://doi.org/10.1002/bies.200900182

Yanamala, N., Tirupula, K. C., \& Klein-Seetharaman, J. (2008). Preferential binding of allosteric modulators to active and inactive conformational states of metabotropic glutamate receptors. BMC Bioinformatics, 9 Supp/ 1, S16.

Yona, G., \& Levitt, M. (2002). Within the twilight zone: a sensitive profile-profile comparison tool based on information theory. Journal of Molecular Biology, 315(5), 1257-1275.

Yosef, O., Popovits, Y., Malik, A., Ofek-Lalzer, M., Mass, T., \& Sher, D. (2020). A tentacle for every occasion: comparing the hunting tentacles and sweeper tentacles, used for territorial competition, in the coral Galaxea fascicularis. BMC Genomics, 21(1), 548.

Zhou, K., Kanai, R., Lee, P., Wang, H.-W., \& Modis, Y. (2012). Toll-like receptor 5 forms asymmetric dimers in the absence of flagellin. Journal of Structural Biology, 177(2), 402-409. 
bioRxiv preprint doi: https://doi.org/10.1101/2021.10.18.464760; this version posted October 28, 2021. The copyright holder for this preprint (which was not certified by peer review) is the author/funder, who has granted bioRxiv a license to display the preprint in perpetuity. It is made available under aCC-BY 4.0 International license. 